\title{
Outcome Measures in Clinical Trials for Multiple Sclerosis
}

\author{
Caspar E. P. van Munster ${ }^{1}$ Bernard M. J. Uitdehaag ${ }^{1}$
}

Published online: 9 February 2017

(C) The Author(s) 2017. This article is published with open access at Springerlink.com

\begin{abstract}
Due to the heterogeneous nature of the disease, it is a challenge to capture disease activity of multiple sclerosis (MS) in a reliable and valid way. Therefore, it can be difficult to assess the true efficacy of interventions in clinical trials. In phase III trials in MS, the traditionally used primary clinical outcome measures are the Expanded Disability Status Scale and the relapse rate. Secondary outcome measures in these trials are the number or volume of T2 hyperintense lesions and gadolinium-enhancing T1 lesions on magnetic resonance imaging (MRI) of the brain. These secondary outcome measures are often primary outcome measures in phase II trials in MS. Despite several limitations, the traditional clinical measures are still the mainstay for assessing treatment efficacy. Newer and potentially valuable outcome measures increasingly used or explored in MS trials are, clinically, the MS Functional Composite and patient-reported outcome measures, and on MRI, brain atrophy and the formation of persisting black holes. Several limitations of these measures have been addressed and further improvements will probably be proposed. Major improvements are the coverage of additional functional domains such as cognitive functioning and assessment of the ability to carry out activities of daily living. The development of multidimensional measures is promising because these measures have the potential to cover the full extent of MS activity and progression. In this review, we provide an overview of the historical background and recent developments of outcome measures in
\end{abstract}

Caspar E. P. van Munster

c.vanmunster@vumc.nl

1 Department of Neurology, Amsterdam Neuroscience, VUmc MS Center Amsterdam, VU University Medical Center, De Boelelaan 1117, 1081 Amsterdam, The Netherlands
MS trials. We discuss the advantages and limitations of various measures, including newer assessments such as optical coherence tomography, biomarkers in body fluids and the concept of 'no evidence of disease activity'.

\section{Key Points}

Capturing disease activity in multiple sclerosis (MS) trials is a challenge and traditional outcome measures all have clear limitations.

Newer measures are being developed and increasingly used in trials.

Multidimensional outcome measures are promising because they have the potential to capture the full extent of disease activity by assessing various functional domains relevant for MS.

\section{Background}

Multiple sclerosis (MS) has a female predominance and typically develops at young age with a peak incidence between 20 and 40 years [1]. Clinically, it is characterized by a large variability of symptoms arising from focal inflammation of the central nervous system that may occur at various points in time. Symptoms generally last for several days to weeks, but occasionally persist for many months, with subsequent full or partial recovery. These periods are referred to as relapses. Radiologically, MS is characterized by typical white matter lesions that are best visualized with magnetic resonance imaging (MRI). The 
occurrence of clinical relapses or new white matter lesions on MRI is used to estimate disease activity.

Demonstrating dissemination in time and place, clinical or radiological, is the core feature of the diagnostic criteria [2].

The occurrence of relapses is the dominant clinical picture in the vast majority of patients during the earlier disease stages and is defined as relapsing-remitting MS (RRMS). If a patient only experienced a single episode with clinical symptoms, it is referred to as a clinically isolated syndrome (CIS). Relapses eventually subside and the disease course often evolves to a slow worsening of symptoms, leading to disability accrual (i.e. disease progression). When there is a disease progression independent from relapses, this is referred to as secondary-progressive MS (SPMS). Approximately $15 \%$ of patients have slowly progressive disease from onset without evident relapses and are categorized as primary-progressive MS (PPMS).The first effective immunomodulatory treatments were the injectables interferon- $\beta$ and glatiramer acetate that were introduced in the 1990s [3]. After a decade, the more potent natalizumab (in 2004) and the first oral drug fingolimod (in 2010) were introduced. More recently approved treatments include teriflunomide, dimethylfumurate, alemtuzumab and daclizumab. Ocrelizumab and cladribine are expected to be approved in the near future. In the phase III trials of these treatments, the outcome measures used to evaluate efficacy were relapse rate, disability worsening and MRI [formation of new T2 hyperintense lesions [T2HL] or gadolinium-enhancing T1 lesions (GdT1L)]. These measures have been generally accepted as measures of (short-term) treatment effects.

Clearly, treatment options in MS are rapidly expanding and are applied in patients with different clinical phenotypes. It is therefore important to have clear, comprehensive and universally accepted outcome measures. For this purpose, an outcome measure has to be valid, reliable and responsive. In practical terms this means it must measure what it intends to measure, it should be free of measurement errors and able to detect true change of performance (due to disease activity or progression) [4]. Furthermore, it needs to capture clinically relevant changes and ideally has predictive value.
Unfortunately, standardized definitions of outcome measures in MS research are lacking, for which there are several explanations. First, the clinical disease expression and course are highly variable, which hampers defining a uniform concept of disability in MS [5-7]. There is wide variation between patients concerning relapse frequency (including seasonal variation [8]) and accrual of (relapserelated) disability. Also, patients may present with virtually all neurological symptoms that exhibit an age-dependent distribution (Table 1) [7]. Moreover, the extent to which symptoms contribute to overall disability is variable. This may be more dependent on the location of the lesion than on the size or activity. For example, a severe persisting hemiparesis may have a greater impact on disability than a mild sensory deficit, while both may result from pathologically comparable lesions. In fact, lesions may occur subclinically without causing disability worsening [9]. Another difficulty is that disability often accumulates slowly. Consequently, long-term follow-up is needed to assess treatment effect, which makes trials time-consuming and expensive. Lastly, disability is influenced by confounding factors that may not be directly related to disease activity (e.g. fatigue, mood disturbances, deconditioning, spasticity and side effects of medication) [10].

With all these difficulties in mind, we aim to provide a non-systematical comprehensive overview of clinical and paraclinical outcome measures that are used in clinical research of MS (summarized in Table 2). We elaborate on traditional and newer measures such as brain atrophy, optical coherence tomography (OCT), biomarkers in body fluids and the concept of 'no evidence of disease activity' (NEDA). We highlight the most important advantages, limitations and caveats of these measures.

\section{Clinical Outcome Measures}

Outcome measures can be generic or disease-specific, physician- or patient-based, direct or indirect, and may cover all or specific aspects of MS. Various clinical outcome measures are available, assessing different disease characteristics. Which characteristics are important largely

Table 1 Distribution of patients (\%) by presenting clinical symptoms and age of onset [7]

\begin{tabular}{|c|c|c|c|c|c|c|}
\hline $\begin{array}{l}\text { Age at onset of } \\
\text { MS (years) }\end{array}$ & $\begin{array}{l}\text { Optic } \\
\text { neuritis }\end{array}$ & $\begin{array}{l}\text { Diplopia } \\
\text { or vertigo }\end{array}$ & $\begin{array}{l}\text { Acute motor } \\
\text { symptoms }\end{array}$ & $\begin{array}{l}\text { Insidious motor } \\
\text { symptoms }\end{array}$ & $\begin{array}{l}\text { Balance or } \\
\text { limb ataxia }\end{array}$ & $\begin{array}{l}\text { Sensory } \\
\text { symptoms }\end{array}$ \\
\hline$<20$ & 23 & 18 & 6 & 4 & 14 & 46 \\
\hline $20-29$ & 23 & 12 & 7 & 6 & 11 & 52 \\
\hline $30-39$ & 13 & 11 & 7 & 14 & 15 & 44 \\
\hline $40-49$ & 9 & 17 & 3 & 31 & 13 & 33 \\
\hline$\geq 50$ & 6 & 13 & 4 & 47 & 11 & 32 \\
\hline
\end{tabular}

$M S$ multiple sclerosis 
Table 2 Primary, secondary and exploratory outcome measures in phase III trials for MS

Primary outcome measures

Clinical Expanded Disability Status Scale (EDSS): 3 or 6 months confirmed disability worsening or improvement

Relapses: annualized relapse rate, time to second relapse (conversion to clinically definite MS)

Secondary outcome measures

\begin{tabular}{ll}
\hline Clinical & MS Functional Composite (MSFC): timed 25-foot walk test, nine-hole peg test, paced auditory serial addition task \\
& or symbol digit modalities test \\
Paraclinical & T2-hyperintense lesions \\
& Gadolinium-enhancing T1 lesions \\
& Whole brain atrophy
\end{tabular}

Exploratory outcome measures

Clinical

Paraclinical—imaging

Paraclinical—biomarkers

Composite

Electronic devices
As candidate component of MSFC: low-contrast letter acuity test

Patient-reported outcome measures: e.g. quality of life, depression and anxiety, fatigue, specific functional domains Volumetric measures of specific structures (e.g. thalamus, upper cervical cord area)

Persisting black holes

Functional MRI for analysis of functional connectivity

Diffusion tensor imaging to examine brain tissue integrity

Magnetization transfer ratio MRI as a marker for brain myelin content

Optical coherence tomography

\section{Biomarkers in body fluids: in CSF or blood}

No evidence of disease activity (NEDA): typically covering (confirmed) EDSS progression, relapse rate and formation of MRI lesions; whole brain volume increasingly included (i.e. 'NEDA-4')

Assess MS system, Glove analyzer, accelerometers, etc.

CSF cerebrospinal fluid, $M R I$ magnetic resonance imaging, $M S$ multiple sclerosis

depends on the aim of the study. Here, we first describe the traditional measures Expanded Disability Status Scale (EDSS) and relapses. Subsequently, the more recently developed Multiple Sclerosis Functional Composite (MSFC) will be discussed. Finally, we elaborate on patientreported outcome measures (PROMs) as these patientbased measures are increasingly being used in MS trials.

\subsection{The Expanded Disability Status Scale}

The EDSS intends to capture disability of MS patients based on neurological examination by describing symptoms and signs in eight functional systems (FS). Furthermore, it encompasses ambulatory function and the ability to carry out activities of daily living (ADL). An overall score can be given on an ordinal scale ranging from 0 (normal neurological examination) to 10 (death due to MS). Scores from 0 to 4.0 are determined by FS scores, which means that in this range the EDSS is essentially a measure of impairment. Scores from 4.0 higher basically address disability. Ambulatory function and the use of walking aids heavily determine the range of 4.0-7.0, and scores between 7.0 and 9.5 are largely determined by the ability to carry out ADL. A schematic representation of the EDSS is given in Fig. 1.
In clinical trials of MS, the EDSS is the most widely used outcome measure to determine disability worsening and define relapse-related change in neurological function. Furthermore, it is used as an inclusion criterion and to characterize study populations. The value of the EDSS as a surrogate outcome measure for future disability is limited [11-15].

\subsubsection{Limitations and Caveats}

Despite general acceptance of the EDSS, there are many limitations and caveats (summarized in Table 3) [16]. First of all, EDSS holds high intra- and inter-rater variability $[10,11,17-19]$. This can be explained by the subjective nature of the neurological examination itself on which the EDSS is largely based, particularly in the lower EDSS range. Also, complex and ambiguous scoring rules for the FS probably explain some of the variability.

Non-linearity of the EDSS is another limitation (visualized in Fig. 1). The staying time in the middle scores is shortest and this results in a bimodal distribution with peaks at 1.0-3.0 and 6.0-7.0 [7, 20]. It means that the rate of progression as assessed by the EDSS varies depending on baseline score. Furthermore, responsiveness of the 


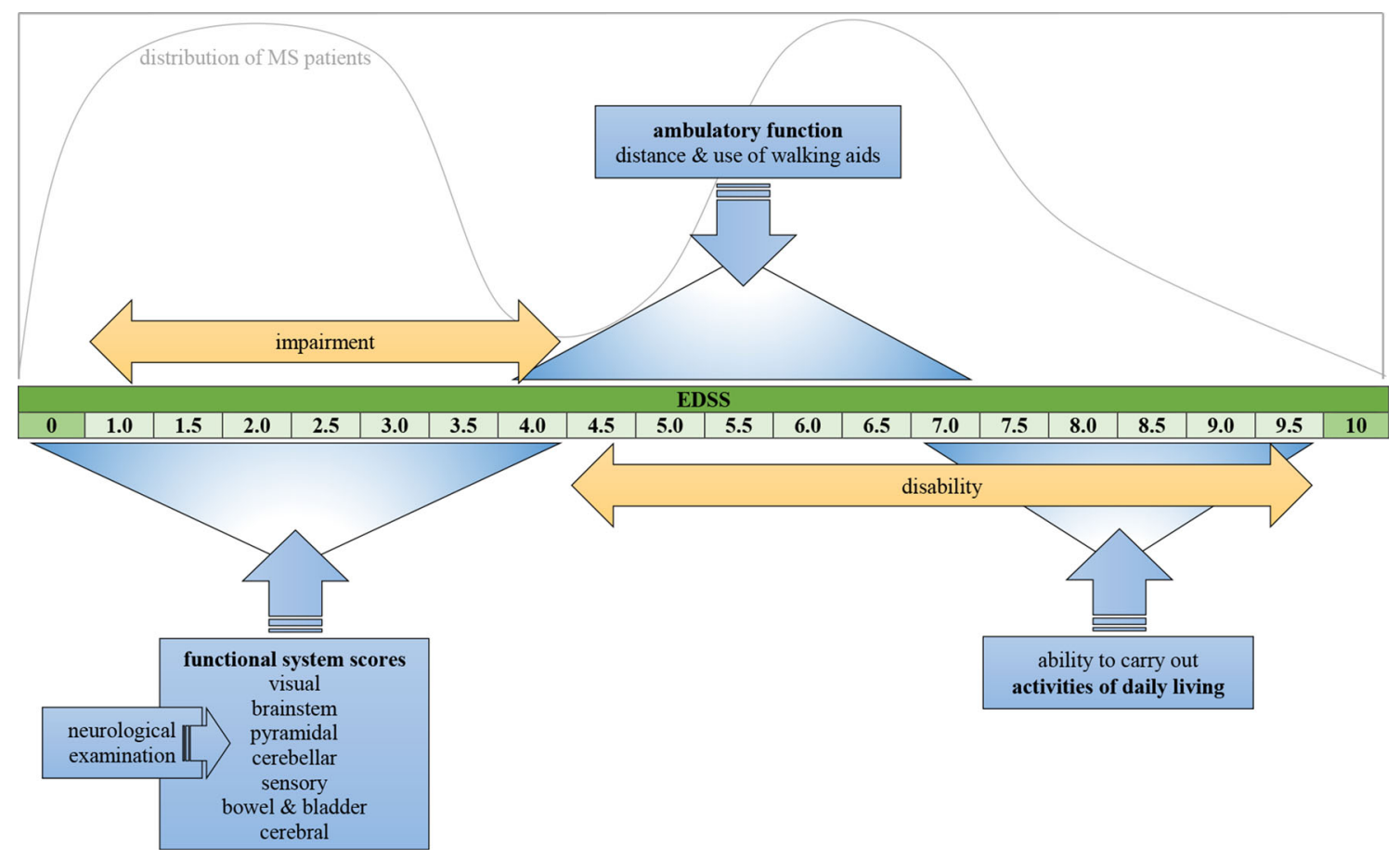

Fig. 1 Schematic representation of Expanded Disability Status Scale (EDSS) depicting the factors that determine overall score; the graph shows the distribution of patients over the EDSS [7]. MS multiple sclerosis

EDSS is limited [16, 21]. Scores higher than 4.0 are less influenced by changes in FS scores. For example, development of a paresis in a patient with an EDSS of 6.0 will not result in a higher EDSS. Conversely, EDSS would have changed with a baseline EDSS of 4.0.

The non-linearity and limited responsiveness should both be accounted for when interpreting changes over time [22]. Nevertheless, EDSS change is often presented without accounting for the baseline score. As a result, statistically significant change may erroneously be presented as clinically relevant and vice versa. An increasingly used clinically meaningful change is a change of 1.0 or more if EDSS at baseline was 0 to 5.5, and 0.5 or more for higher baseline EDSS scores. This is more driven by reproducibility data than by clinical relevance data.

Because the EDSS is an ordinal scale, non-parametric statistics should be used in statistical analysis. This implies that significant differences between groups can be calculated, but the magnitude of differences cannot. In line with this, results should not be presented with means and standard deviation, but with median values and interquartile ranges. Also, a caveat of numeric values is that they might give the false impression of being precise.

Another limitation is that clinical phenotypes are unevenly distributed across the EDSS. Because ambulatory dysfunction is one of the main characteristics in patients with progressive disease (SPMS and PPMS), these patients represent a larger proportion in the range of 4.0-7.5 [23, 24].
Lastly, several domains are not (sufficiently) assessed. Examples are cognitive function, mood, energy level and quality of life. Symptoms in these domains are frequently observed in MS patients and they may influence FS scores, ambulation and ADL function.

\subsubsection{Suggested Improvements}

During the International Conference on Disability Outcomes in MS (ICDOMS) that was held in 2011, several refinements for the EDSS were suggested to improve performance [25]. Firstly, a standardized script for questioning patients (which is necessary for some FS scores) might improve reliability and decrease the risk of unblinding in clinical trials (an example of the Neurostatus form may be found on http://www.neurostatus.net/). Secondly, simplification of scoring rules might reduce intra- and inter-rater variability. Thirdly, long-term disability worsening should be assessed with confirmation of EDSS worsening at 6 rather than 3 months. The main reason for this is that relapses may improve beyond 3 months, and thus EDSS worsening may be temporary [26]. Fourthly, streamlining of the EDSS might be achieved by finding the components of FS that contribute most to confirmed worsening of disability and omitting the other less informative components. Lastly, modification of the EDSS to improve linearity of measurement will facilitate statistical analysis and clinical understanding. 
Table 3 Limitations, caveats and improvements for clinical outcome measures

Limitations and caveats Improvements

\section{Expanded Disability Status Scale (EDSS)}

High intra- and inter-observer variability

Non-linearity (bimodal distribution)

Limited responsiveness

Necessity to use non-parametric statistics (ordinal scale)

Uneven distribution of relapsing-remitting and progressive patients

Several functional domains not assessed

\section{Relapses}

Strong subjectivity

Recovery of signs or symptoms before confirmation of relapse

Recall bias of patient and observer bias of examiner

Newly reported symptoms not always clearly depicted in change of the EDSS

Identification largely depends on patient reporting it

Higher relapse rate prior to inclusion: over-reporting to fulfil inclusion criteria, high relapse rate inclusion criterion leading to decrease of relapse rate because of regression to the mean, placebo effect, decrease of relapse due to natural course of MS

\section{Multiple Sclerosis Functional Composite (MSFC)}

Moderate reliability, sensitivity and responsiveness of the PASAT

The PASAT often disliked by patients, requirement of mathematical ability and ceiling effect

Several important functional domains are not assessed

Lack of a clear dimension of the overall score (resulting in difficult interpretability)

$Z$ scores are influenced by results of the reference population and obscure the meaning of crude scores

\section{Patient-reported outcome measures (PROM)}

Unblinded nature

Potential expectance bias

Assessment of quality of life may be influenced by multiple factors

Possible response shift over time
Accounting for baseline score when determining change (e.g. change $\geq 1.0$ with baseline score $0-5.5$, and $\geq 0.5$ for higher baseline scores)

Determining disability worsening with confirmation of the EDSS progression after at least 6 months

Using standardized scripts for questioning patients (improving reliability and decreasing risk of unblinding)

Simplification of scoring rules (decreasing variability)

Streamlining by stripping components of the functional systems that are less informative

Modification to improve linearity and facilitate statistical analysis

Confirming a relapse by another examiner

Increasing number of visits to identify more relapses

Replacing the PASAT with the symbol digit modalities test Adding the low-contrast letter acuity test (covering visual domain) Adding other functional domains

Determining minimal clinically relevant changes of the $Z$ scores and confirming change after 6 months

Determining clinical relevance

Keeping elements separated instead of combining them into a single score

Weighing of individual questions appropriately

Using (computer) adaptive testing to reduce test length and improve tolerability

$M S$ multiple sclerosis, PASAT paced auditory serial addition task

Whatever its limitations, the EDSS will probably continue to be the main disability measure for the near future because of the vast experience with it and the possibility of making historical comparisons. Until we have better alternatives, clinical assessment can be improved by using the EDSS in conjunction with other measures.

\subsection{Relapses}

The other traditional outcome measure is assessment of relapses. By consensus, a relapse has been defined as new or worsening neurological symptoms that are objectified on neurological examination in the absence of fever and last for more than $24 \mathrm{~h}$, and have been preceded by a period of clinical stability of at least 30 days, with no other explanation than MS [27, 28].

The relationship between number of relapses and disability worsening is not completely clear, although conclusions may be drawn from natural history studies. Various of these studies showed that relapses early in the course of MS were associated with long-term disability and increased risk of conversion to SPMS, which probably 
relates to faster disability worsening [29-32]. However, superimposed relapses in the progressive phase did not lead to faster disability worsening [33].

Treatment effects on relapses are confined to the change in annualized relapse rate or time to second relapse (i.e. conversion to clinically definite MS) [34]. Treatment effect on relapses gives a fair reflection of short-term efficacy.

\subsubsection{Limitations and Caveats}

There are several caveats when using relapses as an outcome measure (summarized in Table 3). First of all, identification of a relapse is subjective. Ensuring perfect blinding for treatment is therefore essential. To limit subjectivity, a second assessment can be performed to objectify the relapse. The problem with this approach is that symptoms or signs may already have recovered, and recall bias of the patient and observer bias from the examiner may influence the second assessment [35].

Another caveat is that identification of a relapse largely depends on a patient reporting new symptoms. When a patient only reports new symptoms on scheduled visits and not spontaneously, the established relapse rate will be lower than in reality. In fact, increasing the number of visits in a trial period may increase the relapse rate [36].

An interesting phenomenon is that relapse rate is often remarkably high prior to inclusion into trials. Various explanations may be given for this [37, 38]. First of all, relapses in the preceding period of a trial are usually determined retrospectively and patients may over-report the exact number to qualify for inclusion. Secondly, the inclusion criterion of relapse rate is often high, meaning that only patients with very active disease are included. As a consequence, it can be expected that the relapse rate of these patients will decrease towards a disease average during the trial (i.e. regression to the mean). Thirdly, patients participating in a trial may do better merely because of a placebo effect or better comprehensive care during the trial. Lastly, during the natural course of MS the relapse rate will eventually decrease, independent of treatment [39]. These factors may obscure the interpretation of absolute relapse rate reduction in treatment trials.

\subsection{The Multiple Sclerosis Functional Composite}

Because of the limitations of the EDSS and assessment of relapses, the MSFC was developed to improve clinical assessment [40, 41]. It was introduced in the early 1990s, a time when the first effective treatments were introduced. In contrast with the EDSS, the MSFC covers three functional domains: ambulatory, hand and cognitive function (a schematic summary is given in Fig. 2). The results of the tests that assess these domains are depicted in an interval scale (seconds or number of correct responses) and can be converted to a $Z$ score that is based on values of a reference population [42]. An overall score can be calculated by averaging the $Z$ score of the subtests.

The MSFC has been extensively evaluated. The overall score of MSFC correlated strongly with EDSS [43] and subtest scores did moderately [40]. Also, change of MSFC correlated with EDSS change and relapse rate [40, 44, 45]. Furthermore, it was predictive of conversion from RRMS to SPMS [44]. Concerning the relation with MRI abnormalities, MSFC correlated with white matter lesion load and various atrophy measures [46-48]. Lastly, correlations with several PROMs [43, 49-51], employment status [52] and driving performance [53] were found.

\subsubsection{The Original Components}

Ambulatory function is tested with the timed 25 -foot walk test (T25W, explained in Table 4). The T25W is a reliable test for patients with more severe gait impairment, because it primarily assesses walking speed. Assessing walking speed seems clinically relevant, because it relates to the capacity to perform outdoor activities important in daily life [54]. For patients with mild gait impairment, the T25W may not be sensitive enough to detect abnormalities and because of that has a floor/ceiling effect [55]. For these patients, it may be more appropriate to assess walking endurance with longer walking distances; for example, with a 6-minute walking test [56].

Hand function is tested with the nine-hole peg test (9HPT, explained in Table 4). A change of 9HPT correlated with long-term disability [57].

The paced auditory serial addition task (PASAT, explained in Table 4) was originally included to cover the cognitive domain [58]. It measures processing speed and working memory, both of which are frequently affected functions in MS patients [59]. The test has moderate reliability and sensitivity for detection of cognitive impairment, and has limited responsiveness to change [60]. Furthermore, it requires a certain mathematical ability and has a clear ceiling effect $[49,61]$. Finally, it is often disliked by patients because the time limit induces stress.

\subsubsection{Candidate Components}

A candidate cognitive test that may replace the criticized PASAT is the symbol digit modalities test (SDMT, explained in Table 4) [62, 63]. It measures information processing speed. The advantages of the SDMT are that it is easily administered, better tolerated by patients (probably because there is no time pressure) [64] and more robust and reliable than the PASAT $[65,66]$. Moreover, the SDMT correlated more strongly with white matter 


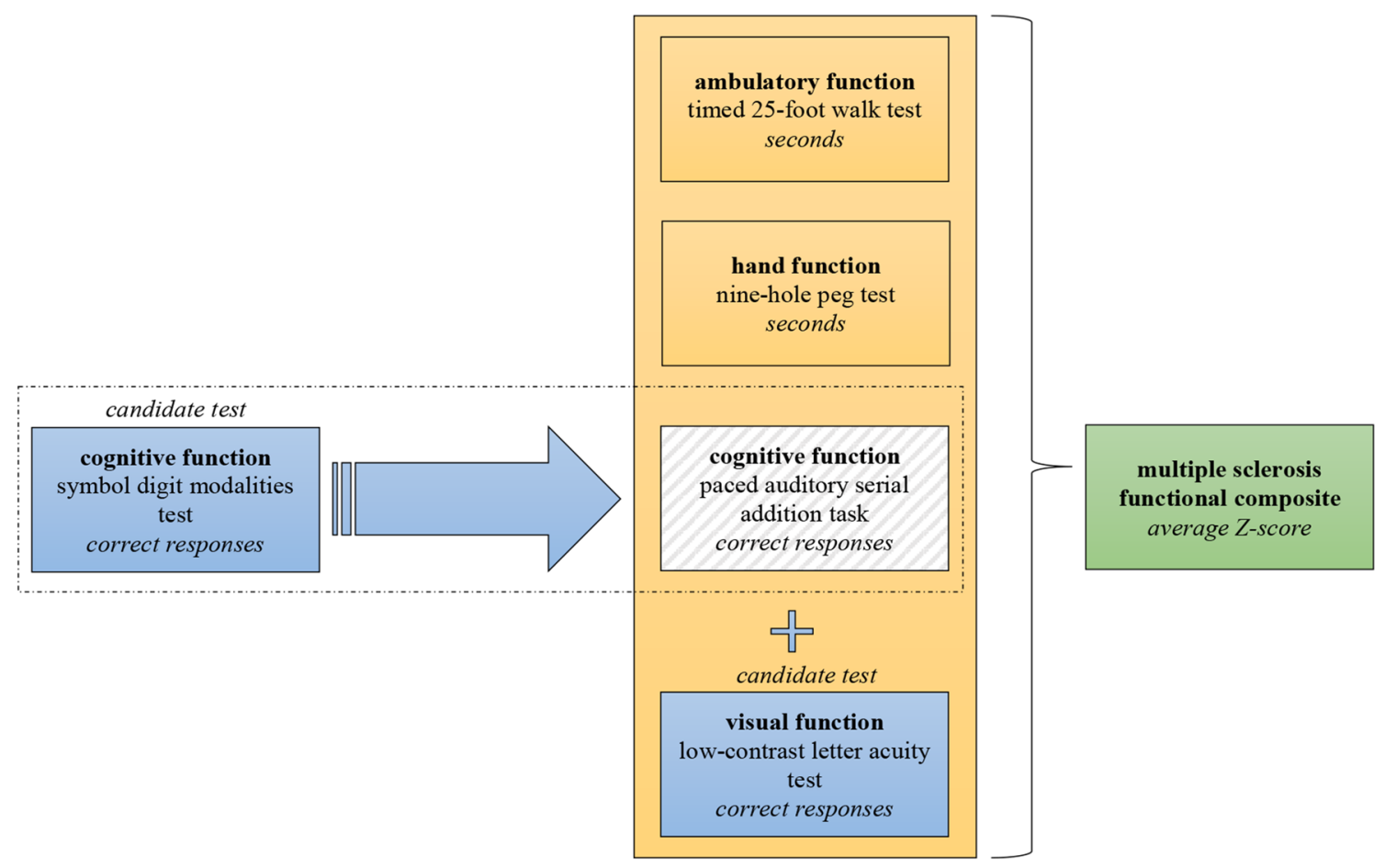

Fig. 2 Schematic representation of the Multiple Sclerosis Functional Composite (MSFC) with candidate components

Table 4 Description of components of the Multiple Sclerosis Functional Composite (MSFC)

Original components

Timed 25-foot walk test (T25W) The patient is directed to one end of a clearly marked 25-foot course and is instructed to walk 25 feet as quickly as possible, but safely. The task is immediately administered again by having the patient walk back the same distance. Patients may use assistive devices when doing this task. In clinical trials, it is recommended that the treating neurologist select the appropriate assistive device for each patient [42]

Nine-hole peg test (9HPT)

The patient is asked to take nine small pegs one by one from a small shallow container, place them into nine holes and then remove them and place them back into the container. Results are depicted in seconds to complete the task of both the dominant and non-dominant hand; two trials for each side [42]

Paced auditory serial addition

The PASAT is presented on audiocassette tape or compact disc to control the rate of stimulus presentation. task (PASAT) Single digits are presented either every $3 \mathrm{~s}$ (or every $2 \mathrm{~s}$ for the optional 2-second PASAT) and the patient must add each new digit to the one immediately prior to it. The test score is the number of correct sums given (out of 60 possible) in each trial. To minimize familiarity with stimulus items in clinical trials and other serial studies, two alternate forms have been developed; the order of these should be counterbalanced across testing sessions. The PASAT is the last measure of the MSFC that is administered at each visit [42]

Candidate components

Symbol digit modalities test (SDMT)

Low-contrast letter acuity test (LCLA)
Patients are presented with a key that includes nine numbers, each paired with a different symbol. Below this key is an array of these same symbols in pseudo-random order paired with empty spaces. Patients must then provide the correct numbers that accompany the symbols as indicated in the key [64]

Seven charts with different levels of contrast $(0.6-100 \%)$ are presented to the patient. On each chart, multiple rows are depicted with gray letters with decreasing size on a white background. The letter scores indicate the number of letters identified correctly. Each chart is scored separately abnormalities than PASAT [67, 68]. It also correlated with worsening of cognitive impairment [69, 70] and MRI abnormalities (atrophy measures in particular) [71, 72]. A limitation is that a patient has to have an intact visual system, which may be impaired in MS patients. Although there is a ceiling effect, it is less pronounced than for the 
PASAT. All points considered, the SDMT is probably a good replacement for the PASAT.

When the MSFC was developed, no data on suitable tests to assess visual function were available. In the past decade, various visual outcome measures for MS research have been studied [73]. Of these, the low-contrast letter acuity test (LCLA, explained in Table 4) may be a good candidate to add to the MSFC [74]. Results correlated with clinical phenotypes, MRI abnormalities and PROMs for visual impairment and quality of life (which supports clinical relevance) $[75,76]$. Moreover, some clinical trials showed treatment effect on the LCLA in the active group compared with placebo [77].

\subsubsection{Limitations and Caveats}

There are several limitation and caveats of the MSFC (summarized in Table 3). A frequently postulated objection to the MSFC is that the overall score lacks a clear dimension, which hinders interpretability and therefore appears to be difficult for the interpreter to get familiar with the score. In other words, it is difficult to form a 'mental picture' of it [78]. This difficulty may be addressed by keeping the elements of the MSFC score separated instead of combining them into a single score. Nonetheless, comparison of subtest results between studies remains impossible due to the $Z$ scores that obscure the meaning of crude scores.

Another problem is that results from the reference group strongly influence the $Z$ scores of patients [79]. With that, assessing changes in time is problematic, because the overall score is influenced by variability between time points of both the reference and patient group. Consequently, it is impossible to determine if change is a result of statistical variance or true progression of disability [38].

A potential solution to some of the statistical caveats of $Z$ scores might be to determine the minimal clinically relevant change [21, 80]. This means that change should be confirmed on a subsequent time point, preferably at 6 months (because of possible disability improvement after a relapse). This approach has been tested in a clinical trial dataset [45]. Sensitivity of worsening was found to be similar between MSFC and EDSS, and it correlated with other clinical and MRI outcome measures. However, the downside of this approach is that it will hamper sensitivity to change, which is of particular importance in patients with severe disability.

Despite its disadvantages, the MSFC is an appealing alternative for the EDSS. It can be performed within 20 minutes, covers three domains, has good intra- and interrater reliability and it results in a score on a continuous scale. The MSFC has been used as the primary outcome in a treatment trial in SPMS [49]. While MSFC progression was slowed, treatment effects were not observed with the EDSS. If the components are applied in a sensible way, the MSFC may be used as the primary endpoint in future clinical trials.

\subsection{Patient-Reported Outcome Measures}

A PROM is defined as "any report of a patient's health condition that comes directly from the patient, without interpretation of the patient's response by a clinician or anyone else" [81].

A PROM may provide valuable insight into the patient perspective of a treatment or matter of interest. For example, treatment success for a patient might be more influenced by adverse events than a physician perceives or deduces from other outcome measures. Furthermore, it may detect clinically meaningful changes and leave out changes with no clinical relevance. A PROM can assess perceived efficacy, side effects, depression and anxiety, fatigue, mobility, quality of life, ability to carry out ADL, sexual dysfunction and symptoms specific for MS. A list of PROMs that are being used in MS research is presented in Table 5 [82-105].

PROMs that assess the ability to carry out ADL may be of particular value. They are able to demonstrate clinical relevance of MS-specific outcome measures. For example, one study found a correlation between the EDSS and a 42-item ADL scale that was mostly driven by impairment of mobility [106]. Another advantage is that measuring ADL activity allows comparison between studies of MS as well as other diseases. Currently, no MS-specific ADL measures are available. Nevertheless, PROMs that were developed for stroke patients (Ranking scale [107, 108] and Bartel index [109]) were used in some MS trials [110, 111].

There are several limitations of PROMs (summarized in Table 3). Among these are their unblinded nature and potential expectance bias. Also, questionnaires assessing quality of life are prone to being influenced by more than just disability. Other factors that are commonly seen in MS patients contribute as well (e.g. fatigue, depression, anxiety and physical comorbidities) [112]. Also, the individual questions should be weighted appropriately. Summing up all the subscores assumes equal importance which is generally not the case. Lastly, PROMs are prone to response shift over time [113]. Response shift occurs when a patient answers an item differently from their previous responses due to a change of internal standards, values or conceptualization of the purposed domain (e.g. quality of life).

Typically, PROMs are fixed in length and all patients have to fill in the complete questionnaire. The number of questions that have to be answered can be reduced with computer adaptive testing [114]. It leads the patient through an iterative process in which the answer to a 
Table 5 Patient-reported outcome measures that are used in MS research

\begin{tabular}{l}
\hline Measure \\
\hline Quality of life \\
MS Quality of Life-54 [103] \\
MS Quality of Life Inventory [86] \\
European Quality of Life-5D [87] \\
Health Utilities Index Mark 3 [87] \\
World Health Organization Quality of Life Brief Form [100] \\
Sickness Impact Profile [83] \\
Life Satisfaction Questionnaire [96] \\
Hamburg Quality of Life Questionnaire in MS [91] \\
Quality of Life Index [85] \\
Leeds MS Quality of Life Scale [90] \\
Disability and Impact Profile [101] \\
The MS International Quality of Life Questionnaire [102] \\
Functional Assessment of MS [84] \\
Depression and anxiety \\
Beck Depression Inventory [82] \\
Patient Health Questionnaire-9 [95] \\
Hospital Anxiety and Depression Scale [94] \\
Fatigue \\
Modified Fatigue Impact Scale [89] \\
Fatigue Impact Scale for Daily Use [88] \\
Single functional domain \\
MS Walking Scale-12 [93] \\
Arm Function in MS Questionnaire [98] \\
Visual Function Questionnaire-25 [99] \\
Guy's Neurological Disability Scale [97] \\
MS Impact Profile [105] \\
Murt Form-36 [104]
\end{tabular}

MS Multiple sclerosis

question determines what question is presented next. For example, if a patient is fully dependent on a wheelchair, a question about climbing stairs is irrelevant. With these methods, patients' tolerability for a questionnaire may be improved.

\section{Paraclinical Outcome Measures}

Numerous paraclinical outcome measures are available and could be used as adjunct to clinical measures to obtain information on treatment efficacy. Some are potentially valuable (e.g. cerebrospinal fluid [CSF], visual evoked potentials) while others are less suitable (e.g. brainstem auditory evoked potentials) [115]. Here, we shortly discuss the value of white matter pathology as detected on MRI.
Subsequently, we will elaborate on newer outcome measures, such as brain atrophy, persisting black holes (PBH), OCT and biomarkers in body fluids.

\subsection{Magnetic Resonance Imaging}

\subsubsection{White Matter Pathology}

MRI is sensitive to detect, characterize and quantify lesions in the white matter. It plays a fundamental role in the McDonald diagnostic criteria for MS to demonstrate dissemination in time and space in addition to clinical signs [2]. Radiological dissemination in space is defined as having at least one lesion in at least two typical (for MS) areas in the central nervous system. Dissemination in time is determined when at least one new lesion is demonstrated on a follow-up MRI, or if one asymptomatic gadoliniumenhancing and one non-enhancing lesion are demonstrated on the initial MRI.

The MAGNIMS workgroup recently proposed a revision of these criteria allowing even earlier diagnosis with MRI [116]. The value of MRI as a diagnostic tool is principally the high sensitivity to detect (past) disease activity. Formation of new T2HL and GdT1L may occur subclinically and are thus more frequently seen than clinical relapses $[9,117]$. The moderate correlation of T2HL load with relapse rate $[26,118]$ and disability $[119,120]$ is possibly related to this phenomenon. Nevertheless, white matter pathology has predictive value for the clinical disease course. For example, patients with a CIS and a high T2HL load at baseline had an increased risk of reaching an EDSS of 3.0 [121]. Also, the presence of two or more GdT1L in patients treated with interferon- $\beta$ predicted EDSS worsening at 15 years [122].

Because of the high sensitivity for detecting disease activity, MRI has been widely accepted as a secondary endpoint in clinical trials. Moreover, demonstrating efficacy on MRI lesions is crucial in the development of immunomodulatory treatments. Treatment effects on MRI could also act as a surrogate endpoint for clinical disease activity. A study supported this by showing that treatment effect on MRI activity explained $>80 \%$ of the variance of treatment effect on relapse rate [123]. Other studies confirmed this by showing the related MRI effects on relapse rate and accumulation of disability worsening (up to 16 years) [124-126].

These classical MRI parameters largely depict (past) neuroinflammation in MS. However, the neurodegenerative aspect of MS is being increasingly studied with MRI. One reason for this is that with the current therapy we are now able to suppress neuroinflammation effectively, but the ultimate goal of therapy is prevention of neuronal tissue loss or, in the long run, to stimulate neuronal repair. 
Another reason is that neuropathological and MRI techniques have improved our insight into the underlying neurodegenerative processes of MS [127]. Consequently, measures that reflect these processes are more frequently used as secondary outcome measures. The most widely used neurodegenerative MRI measures are atrophy and $\mathrm{PBH}$.

\subsubsection{Atrophy}

Brain volume loss in MS patients occurs considerable faster than in healthy people: $0.5-1.0 \%$ versus $0.1-0.3 \%$ brain volume loss per year [128, 129]. Atrophy may be found throughout the disease course, even in the early phases [130]. Remarkably, the atrophy rate of gray matter structures accelerates in patients with SPMS to 14-fold that of healthy persons [131]. Virtually all gray matter structures are affected, although variation exists between clinical phenotypes [132].

Brain volume can be visualized in various ways. The somewhat older measures assess loss of brain volume indirectly by measuring corpus callosum size [133], bicaudate ratio [72] and ventricular volumes [72, 133]. Also, whole brain volume can be measured directly with conventional MRI [72, 128]. Nowadays, segmentation of the brain into white and gray matter compartments or specific gray matter structures is possible and several automated methods reduced processing time [134-136].

The relationship between atrophy measures and clinical signs has been extensively investigated. Whole brain and gray matter atrophy correlated strongly with disability and cognitive impairment, both cross-sectionally and longitudinally [132]. These correlations existed throughout the disease course and clinical phenotypes. Atrophy of gray matter structures may even be more closely related to clinical signs than white matter lesions or whole brain atrophy [137]. Atrophy of several structures correlated remarkably strongly with certain clinical symptoms. For example, cerebellar gray matter atrophy correlated strongly with cerebellar symptoms and hand function [138], upper cervical cord area with ambulatory dysfunction [139], and hippocampal atrophy with memory deficits [140]. Thalamic volume showed a remarkably firm correlation with cognitive impairment [141]. Also, various atrophy measures showed predictive value for future disability and cognitive impairment [137, 142-144].

Furthermore, spinal cord volumes can be assessed, for which the upper cervical cord area is often used. Several studies showed a correlation between spinal cord volume loss and clinical disability [144-146]. It has also been correlated with long-term disability [147].

An extensive summary of clinical trials that used brain atrophy as a secondary endpoint may be found elsewhere
[148, 149]. Noteworthy is a recent meta-analysis that showed that $75 \%$ of the variance of treatment effect on disability was explained by whole brain atrophy and T2HL [150]. Another meta-analysis found evidence that whole brain atrophy in patients that received immunomodulatory treatment was lower than in the placebo group [151].

Although volumetric measurements are appealing outcome measures, there are some caveats and limitations. Firstly, atrophy accumulates very slowly, which generally means that longer follow-up is needed to detect significant changes. Clearly, this accounts particularly for treatment effects on smaller structures, such as thalamic volume. Secondly, the short-term effect of immunosuppression on brain tissue may cause a decrease in brain volume due to resolution of inflammation. This volume loss is not a sign of neurodegeneration, because there is no loss of neuronal tissue. This is often referred to as 'pseudo-atrophy'. Importantly, this effect may last up to 1 year after initiation of treatment [152, 153]. Thirdly, various physiological variations in the content of the intra- and extra-cellular compartments affect volumetric measurements [154]. Lastly, factors that are not MS-specific (such as dehydration, alcohol use, smoking, genetic variation, comorbidities and age) may influence brain volume [154].

\subsubsection{Persisting Black Holes}

Another MRI marker for neurodegeneration is formation of PBH. These lesions are often defined as non-enhancing T2HL with persisting signal intensity between that of the gray matter and the CSF on T1-weighted scans [155]. Approximately $30-40 \%$ of active T2HL will eventually evolve into PBH within 6-12 months [156]. The underlying neuropathology of $\mathrm{PBH}$ is severe and irreversible tissue damage [156]. Accumulation of PBH is associated with accrual of disability $[157,158]$. Furthermore, the PBH load correlated with disability worsening over 10 years [159]. Some clinical trials found significant effects of treatment on the formation of PBH [160-163].

Several more advanced MRI techniques are potentially valuable outcome measures, although they need further research to clarify the exact relevance. Examples are functional MRI for analysis of functional connectivity [164], diffusion tensor imaging to examine brain tissue integrity [165] and magnetization transfer ratio MRI as a marker for brain myelin content [166, 167].

\subsection{Optical Coherence Tomography}

The retina can be visualized non-invasively, safely and fast with OCT. This technique uses the reflection of near infrared light on the retina. Different layers of the retina can be distinguished on high-resolution images. It has been proven 
to be valuable in quantifying pathology in these layers, although the exact underlying pathophysiological processes of these findings are largely unclear [168, 169].

Most findings of the research with OCT in MS point to neurodegenerative changes such as axonal loss and neuronal soma shrinkage [170]. Therefore, OCT is a good candidate outcome measure to assess treatment effect on neurodegeneration, which makes it an attractive tool in progressive MS trials. For this purpose, the retinal nerve fibre layer (RNFL) is of particular interest. The thickness of this layer may be decreased following optic neuritis [171, 172], but also decreases more slowly in patients without prior optic neuritis $[171,173]$. The latter may indicate ongoing neurodegeneration. Furthermore, RNFL thickness correlated with cerebral atrophy measures $[174,175]$ and with axonal loss in the anterior visual pathway [176, 177].

Clinically, thinning of the RNFL correlated with worse performance on the LCLA (explained in Table 4) [171, 178], and a reduced visual quality of life [179]. Correlations of RNFL thickness with EDSS were less consistent [180, 181]. In a recent large multicenter study of patients without prior optic neuritis, persons with a RNFL thickness in the lowest tertile at baseline had double the risk of disability worsening in 2 years compared with the other tertiles [182]. The risk further increased with a longer follow-up. The clinical relevance of other layers, such as macular volume [183] and retinal ganglion-cell/inner plexiform layer thickness [184, 185], is less clear.

The advantage of OCT over MRI is that it is technically easier and widely accessible. When using a predefined scanning protocol, it has good reliability [186]. Nevertheless, further research is needed before OCT can be implemented as an outcome measure. This is particularly the case for longitudinal data of the various layers.

\subsection{Biomarkers in Body Fluids}

Both MRI and OCT allow detection of neuroinflammation and neurodegeneration at various time points, but have limited sensitivity to detect ongoing processes. Biomarkers in body fluids, such as CSF and blood, might be more useful for this purpose. Although it is beyond the scope of this review to discuss this topic thoroughly (it was recently reviewed elsewhere [187]), a few biomarkers are worth mentioning.

There are several potentially valuable CSF biomarkers that might give a real-time reflection of ongoing neurodegeneration. A biomarker that reflects axonal injury is neurofilament. This protein is a major component of the axonal cytoskeleton and is released following neuronal damage [188]. Neurofilament levels in CSF are generally raised in MS patients, particularly during an acute relapse
[189, 190]. Furthermore, increased levels were associated with worse EDSS [190], faster disability worsening in 15 years [191], gadolinium-enhancing lesion load [192] and atrophy (of the brain and spinal cord) in 15 years [193]. Neurofilament levels were also responsive to treatment with fingolimod [194] and natalizumab [195], and therefore might be biomarkers for treatment effect.

Other proteins of the axonal cytoskeleton that can be measured in CSF are actin [196, 197] and tubulin [197, 198]. Proteins that indicate ongoing disease activity are sphingolipids (component of the myelin sheet) [199], glial fibrillary acidic protein (GFAP) [200], S100B [200] and Chitinase 3-like proteins [201].

Compared with CSF, blood is generally less well studied for biomarkers, but clearly has the advantage that it is much easier to obtain. As in CSF, neurofilament in the blood might act as a biomarker for neurodegeneration. Neurofilament levels predicted recovery of spinal cord lesions [202], and higher concentrations were associated with faster conversion to definite MS and more cerebral lesions [203]. Another biomarker that is used to determine bioactivity of interferon- $\beta$ is myxovirus-resistance protein $\mathrm{A}(\mathrm{MxA})$. It also seems to be indicative of recent and future disease activity [204, 205]. Lastly, various small noncoding microRNAs are potentially valuable for predicting disease course and treatment response [187].

The exact value of these biomarkers as outcome measures will have to be determined. If clinically meaningful, they will probably be used in combination with other measures. They may be particularly useful to assess treatment effects in trials with progressive MS, because identification of progression or neurodegenerative changes remains very challenging.

\section{No Evidence of Disease Activity}

The concept of a 'disease-activity-free status' as the ultimate treatment goal has been used in other medical conditions, including cancer and inflammatory diseases such as rheumatoid arthritis. It implies the absence of measurable disease activity. This concept has been translated to NEDA and is used in more recent MS trials as a secondary outcome measure [206, 207]. It is essentially a multidimensional measure that typically covers (confirmed) EDSS progression, relapse rate and formation of MRI lesions (T2HL or GdT1L). However, any parameter related to disease activity may be added.

A recent study in a cohort of RRMS patients found that NEDA at 2 years had a positive predictive value for absence of disability progression at 7 years of $78 \%$ [207]. Furthermore, the predictive value of NEDA was greater than each of the individual components. Other studies also 
showed that combinations of clinical and MRI parameters had better predictive value for disability progression than individual measures [125, 150, 208-210]. For example, a recent meta-analysis found that treatment effect on T2HL and brain volume combined explained $75 \%$ of the variance of disability progression in 2 years, and this was significantly higher than predictive values of the MRI measures individually [150].

In clinical practice, NEDA-like models are used to identify responders and non-responders to treatment. Examples are the Modified Rio Score [211] and the Canadian Treatment Optimization Recommendation Model [35]. Such tools need to have good long-term predictive power for disability, before a treatment decision can be based on them.

When using NEDA as an outcome measure to assess treatment efficacy, it is important to consider the timing of assessment. The reason for this is that a treatment needs to have had enough time to become effective. This can be illustrated by the finding that $70 \%$ of patients had NEDA 2 years after initiating treatment with natalizumab with baseline assessment after 1 year, compared with 51\% NEDA with a baseline at initiation of therapy [212]. For alemtuzumab timing is different, because the true treatment effect starts after the second infusion cycle, 1 year after the initial course [213]. This issue has implications when determining if NEDA can be a valid outcome measure for disability in the long run.

Although NEDA seems an appealing outcome measure in some ways, it is not yet clear which (functional) domains are important to include and when or how frequently these should be assessed. It should, for example, reflect what is important in daily life for patients. Therefore, including a PROM seems indispensable. Also, markers for neurodegeneration should be involved when tissue loss is considered to be the ultimate treatment goal. Therefore, brain volume is increasingly added to NEDA (referred to as NEDA-4) [214]. However, adding more assessments likely reduces the number of patients fulfilling NEDA, and may raise the bar to a toohigh level resulting in the rejection of highly active, but not perfect, interventions.

Taken together, NEDA will continue to evolve while evidence accumulates about what are valuable outcome measures. Standardization of timing and functional subdomains are imperative for comparison between studies.

\section{Future Perspectives}

The number and quality of outcome measures is increasing, and with that the assessment of treatment efficacy will improve over the coming years. Until new measures are validated and generally accepted, the traditional outcome measures of EDSS and relapse rate will remain primary endpoints in clinical trials. However, it is very unlikely that these measures are sufficient to fully assess treatment efficacy. Eventually, measures that more explicitly capture multiple dimensions (e.g. MSFC and NEDA) will probably become the new standard. They are particularly useful to detect infrequent events (e.g. relapses) or small changes (e.g. brain atrophy and disability worsening) under treatment, which is increasingly important with highly effective therapy. The same accounts for treatment of progressive disease (SPMS and PPMS), in which small and gradual treatment effects can be expected. Moreover, multidimensional measures might decrease duration and size of clinical trials. The caveats of multidimensional measures that have to be taken into account are summarized in Table 6 [25].

In addition to improvement of existing outcome measures, innovative techniques such as electronic devices and mobile device applications are potentially valuable. They allow, for instance, multiple or continuous assessment which might give a more adequate picture of a patient's ability or disability and the impact of the disease on daily living.

Several electronic devices are under development to assess disability. An example of this is the Assess MS system that uses an infra-red camera to register movements of upper and lower limbs, trunk and ambulation for automatic quantification of these movements. Results from a pilot study in MS are promising and these preliminary results are currently being validated with a new high-resolution camera [215]. Another device that has been developed is the Glove analyzer system, which is able to record data from finger movements to assess hand and arm function [216]. Also, accelerometers are potentially useful tools to measure mobility automatically [217]. Apart from other attractive aspects, electronic devices are free of intrarater variability.

Mobile device applications are increasingly being used in the medical field and are also potentially useful in assessing outcomes in MS trials. Applications can be easily distributed and accessible for everyone with a smart phone. They can be used in several ways; for example, for assessing a PROM on a regular basis - up to several times per day. Also, applications may be connected online with investigators to get real-time access to or feedback from a patient's status. This may decrease the number of visits needed or could help decide whether or not face-to-face contact with a patient is needed. In past years, healthcare 'hackathons' (i.e. an acronym of HACKers marATHONS) were organized to stimulate development and integration of medical devices and mobile device applications [218, 219]. However, many of these applications need rigorous 
Table 6 Limitations and caveats of multidimensional measures

Interpretation may not be straightforward, particularly if clinical relevance of (some) components are not immediately obvious

An overall score lacks a clear dimension, which complicates the interpretability of the score

Components should be normalized or weighted without obscuring the clinical meaning

Components may shift in opposite directions (improvement vs harm) which might obscure interpretation of treatment efficacy

Components should capture the expected (biological) effects of the intervention under investigation

Increasing the number of components not necessarily increases sensitivity

Redundant components might cause a large change in the composite score in patients that have symptoms in that domain, while the change

may be smaller or absent in patients with symptoms in other domains

Increasing sensitivity to change does not necessarily lead to higher sensitivity for treatment effects

Dichotomization of the results (e.g. 'no evidence of disease activity') will inherently cause loss of information

scientific validation before they may be considered as outcome measures in clinical trials.

\section{Conclusions}

To conclude, assessing outcome in clinical trials in MS is not straightforward and is therefore a challenging field. Although much has been achieved the past decades, 'old habits die hard' and traditional measures will probably remain the standard in the near future. When more advanced measures have proven their value, they need to earn general acceptance by healthcare providers and especially regulatory agencies. In the end, only multidimensional measures will allow full coverage of disease activity and progression of MS and are thus best suited to assessing treatment efficacy in MS trials.

Acknowledgements The authors wish to thank M.M.P. Wijnen for carefully reading the manuscript.

\section{Compliance with Ethical Standards}

Funding No funding was received for the preparation of this review. Open access was funded by the VU University Medical Center, Amsterdam, as part of the COMPACT agreement between Springer and the Association of Dutch Universities and Academy Institutes.

Conflicts of interest $C E P v M$ has received travel support from Novartis Pharma AG, Sanofi Genzyme and Teva Pharmaceuticals, and honoraria for lecturing and consulting from Biogen-Idec and Merck Serono. BMJU has received consultation fees from BiogenIdec, Novartis Pharma AG, EMD Serono, Teva Pharmaceuticals, Sanofi Genzyme and Roche. The Multiple Sclerosis Centre Amsterdam has received financial support for research from Biogen-Idec, Merck Serono, Novartis Pharma AG, and Teva Pharmaceuticals.

Open Access This article is distributed under the terms of the Creative Commons Attribution-NonCommercial 4.0 International License (http://creativecommons.org/licenses/by-nc/4.0/), which permits any noncommercial use, distribution, and reproduction in any medium, provided you give appropriate credit to the original author(s) and the source, provide a link to the Creative Commons license, and indicate if changes were made.

\section{References}

1. Compston A. McAlpine's multiple sclerosis. 4th ed. Philadelphia: Churchill Livingstone Elsevier; 2005.

2. Polman CH, Reingold SC, Banwell B, Clanet M, Cohen JA, Filippi M, et al. Diagnostic criteria for multiple sclerosis: 2010 revisions to the McDonald criteria. Ann Neurol. 2011;69(2): 292-302. doi:10.1002/ana.22366.

3. McGraw CA, Lublin FD. Interferon beta and glatiramer acetate therapy. Neurotherapeutics. 2013;10(1):2-18. doi:10.1007/ s13311-012-0163-4.

4. Mokkink LB, Terwee CB, Patrick DL, Alonso J, Stratford PW, Knol DL, et al. The COSMIN study reached international consensus on taxonomy, terminology, and definitions of measurement properties for health-related patient-reported outcomes. J Clin Epidemiol. 2010;63(7):737-45. doi:10.1016/j.jclinepi. 2010.02.006.

5. Compston A, Coles A. Multiple sclerosis. Lancet. 2008;372 (9648):1502-17. doi:10.1016/S0140-6736(08)61620-7.

6. Lublin FD, Reingold SC. Defining the clinical course of multiple sclerosis: results of an international survey. National Multiple Sclerosis Society (USA) Advisory Committee on Clinical Trials of New Agents in Multiple Sclerosis. Neurology. 1996;46(4):907-11.

7. Weinshenker BG, Bass B, Rice GP, Noseworthy J, Carriere W, Baskerville J, et al. The natural history of multiple sclerosis: a geographically based study. I. Clinical course and disability. Brain. 1989;112(Pt 1):133-46.

8. Jin Y, de Pedro-Cuesta J, Soderstrom M, Stawiarz L, Link H. Seasonal patterns in optic neuritis and multiple sclerosis: a metaanalysis. J Neurol Sci. 2000;181(1-2):56-64.

9. Barkhof F. The clinico-radiological paradox in multiple sclerosis revisited. Curr Opin Neurol. 2002;15(3):239-45.

10. Amato MP, Fratiglioni L, Groppi C, Siracusa G, Amaducci L. Interrater reliability in assessing functional systems and disability on the Kurtzke scale in multiple sclerosis. Arch Neurol. 1988;45(7):746-8.

11. Ebers GC, Heigenhauser L, Daumer M, Lederer C, Noseworthy JH. Disability as an outcome in MS clinical trials. Neurology. 2008;71(9):624-31. doi:10.1212/01.wnl.00003 13034.46883.16.

12. Freedman MS. Long-term follow-up of clinical trials of multiple sclerosis therapies. Neurology. 2011;76(Suppl 1):S26-34. doi:10.1212/WNL.0b013e318205051d.

13. Goodin DS, Traboulsee A, Knappertz V, Reder AT, Li D, Langdon D, et al. Relationship between early clinical characteristics and long term disability outcomes: 16 year cohort study (follow-up) of the pivotal interferon beta-1b trial in multiple 
sclerosis. J Neurol Neurosurg Psychiatry. 2012;83(3):282-7. doi:10.1136/jnnp-2011-301178.

14. Liu C, Blumhardt LD. Disability outcome measures in therapeutic trials of relapsing-remitting multiple sclerosis: effects of heterogeneity of disease course in placebo cohorts. J Neurol Neurosurg Psychiatry. 2000;68(4):450-7.

15. Rudick RA, Lee JC, Cutter GR, Miller DM, Bourdette D, Weinstock-Guttman B, et al. Disability progression in a clinical trial of relapsing-remitting multiple sclerosis: eight-year followup. Arch Neurol. 2010;67(11):1329-35. doi:10.1001/archneurol. 2010.150 .

16. Hobart J, Freeman J, Thompson A. Kurtzke scales revisited: the application of psychometric methods to clinical intuition. Brain. 2000;123(Pt 5):1027-40.

17. Francis DA, Bain P, Swan AV, Hughes RA. An assessment of disability rating scales used in multiple sclerosis. Arch Neurol. 1991;48(3):299-301.

18. Goodkin DE, Cookfair D, Wende K, Bourdette D, Pullicino P, Scherokman B. Inter- and intrarater scoring agreement using grades 1.0 to 3.5 of the Kurtzke Expanded Disability Status Scale (EDSS). Multiple Sclerosis Collaborative Research Group. Neurology. 1992;42(4):859-63.

19. Noseworthy JH, Vandervoort MK, Wong CJ, Ebers GC, The Canadian Cooperation MS Study Group. Interrater variability with the Expanded Disability Status Scale (EDSS) and Functional Systems (FS) in a multiple sclerosis clinical trial. Neurology. 1990;40(6):971-5.

20. Weinshenker BG, Rice GP, Noseworthy JH, Carriere W, Baskerville J, Ebers GC. The natural history of multiple sclerosis: a geographically based study. 4. Applications to planning and interpretation of clinical therapeutic trials. Brain. 1991;114(Pt 2):1057-67.

21. Hobart J, Blight AR, Goodman A, Lynn F, Putzki N. Timed 25-foot walk: direct evidence that improving $20 \%$ or greater is clinically meaningful in MS. Neurology. 2013;80(16):1509-17. doi:10.1212/WNL.0b013e31828cf7f3.

22. Whitaker JN, McFarland HF, Rudge P, Reingold SC. Outcomes assessment in multiple sclerosis clinical trials: a critical analysis. Mult Scler. 1995;1(1):37-47.

23. Heesen C, Bohm J, Reich C, Kasper J, Goebel M, Gold SM. Patient perception of bodily functions in multiple sclerosis: gait and visual function are the most valuable. Mult Scler. 2008;14(7):988-91. doi:10.1177/1352458508088916.

24. Sutliff MH. Contribution of impaired mobility to patient burden in multiple sclerosis. Curr Med Res Opin. 2010;26(1):109-19. doi:10.1185/03007990903433528.

25. Cohen JA, Reingold SC, Polman CH, Wolinsky JS, International Advisory Committee on Clinical Trials in Multiple S. Disability outcome measures in multiple sclerosis clinical trials: current status and future prospects. Lancet Neurol. 2012;11(5):467-76. doi:10.1016/S1474-4422(12)70059-5.

26. Lublin FD, Baier M, Cutter G. Effect of relapses on development of residual deficit in multiple sclerosis. Neurology. 2003;61(11):1528-32.

27. McDonald WI, Compston A, Edan G, Goodkin D, Hartung HP, Lublin FD, et al. Recommended diagnostic criteria for multiple sclerosis: guidelines from the International Panel on the diagnosis of multiple sclerosis. Ann Neurol. 2001;50(1):121-7.

28. Poser CM, Paty DW, Scheinberg L, McDonald WI, Davis FA, Ebers GC, et al. New diagnostic criteria for multiple sclerosis: guidelines for research protocols. Ann Neurol. 1983;13(3): 227-31. doi:10.1002/ana.410130302.

29. Debouverie M, Pittion-Vouyovitch S, Louis S, Guillemin F, Group L. Natural history of multiple sclerosis in a populationbased cohort. Eur J Neurol. 2008;15(9):916-21. doi:10.1111/j. 1468-1331.2008.02241.x.
30. Eriksson M, Andersen O, Runmarker B. Long-term follow up of patients with clinically isolated syndromes, relapsing-remitting and secondary progressive multiple sclerosis. Mult Scler. 2003;9(3):260-74.

31. Scalfari A, Neuhaus A, Degenhardt A, Rice GP, Muraro PA, Daumer M, et al. The natural history of multiple sclerosis: a geographically based study 10: relapses and long-term disability. Brain. 2010;133(Pt 7):1914-29. doi:10.1093/brain/ awq118.

32. Tremlett H, Yousefi M, Devonshire V, Rieckmann P, Zhao Y, Neurologists UBC. Impact of multiple sclerosis relapses on progression diminishes with time. Neurology. 2009;73(20):1616-23. doi:10.1212/WNL.0b013e3181c1e44f.

33. Confavreux C, Vukusic S, Moreau T, Adeleine P. Relapses and progression of disability in multiple sclerosis. N Engl J Med. 2000;343(20):1430-8. doi:10.1056/NEJM200011163 432001.

34. Sormani MP, Signori A, Siri P, De Stefano N. Time to first relapse as an endpoint in multiple sclerosis clinical trials. Mult Scler. 2013;19(4):466-74. doi:10.1177/1352458512457841.

35. Freedman MS, Selchen D, Arnold DL, Prat A, Banwell B, Yeung M, et al. Treatment optimization in MS: Canadian MS Working Group updated recommendations. Can J Neurol Sci. 2013;40(3):307-23.

36. Thygesen P. Evaluation of drug treatment of disseminated sclerosis. Ugeskr Laeger. 1965;127(45):1448-50.

37. Uitdehaag BM, Barkhof F, Coyle PK, Gardner JD, Jeffery DR, Mikol DD. The changing face of multiple sclerosis clinical trial populations. Curr Med Res Opin. 2011;27(8):1529-37. doi:10. 1185/03007995.2011.591370.

38. Uitdehaag BM. Clinical outcome measures in multiple sclerosis. Handb Clin Neurol. 2014;122:393-404. doi:10.1016/B978-0444-52001-2.00016-9.

39. Confavreux C, Aimard G, Devic M. Course and prognosis of multiple sclerosis assessed by the computerized data processing of 349 patients. Brain. 1980;103(2):281-300.

40. Cutter GR, Baier ML, Rudick RA, Cookfair DL, Fischer JS, Petkau J, et al. Development of a multiple sclerosis functional composite as a clinical trial outcome measure. Brain. 1999;122(Pt 5):871-82.

41. Rudick R, Antel J, Confavreux C, Cutter G, Ellison G, Fischer J, et al. Recommendations from the national multiple sclerosis society clinical outcomes assessment task force. Ann Neurol. 1997;42(3):379-82. doi:10.1002/ana.410420318.

42. Fischer J, Jak AJ, Kniker JE, Rudick R. Administration and scoring manual, revised. New York, Demos Vermande; 2001.

43. Miller DM, Rudick RA, Cutter G, Baier M, Fischer JS. Clinical significance of the multiple sclerosis functional composite: relationship to patient-reported quality of life. Arch Neurol. 2000;57(9):1319-24.

44. Rudick RA, Cutter G, Baier M, Fisher E, Dougherty D, Weinstock-Guttman B, et al. Use of the Multiple Sclerosis Functional Composite to predict disability in relapsing MS. Neurology. 2001;56(10):1324-30.

45. Rudick RA, Polman CH, Cohen JA, Walton MK, Miller AE, Confavreux $\mathrm{C}$, et al. Assessing disability progression with the multiple sclerosis functional composite. Mult Scler. 2009;15(8):984-97. doi:10.1177/1352458509106212.

46. Fisher E, Rudick RA, Cutter G, Baier M, Miller D, WeinstockGuttman B, et al. Relationship between brain atrophy and disability: an 8-year follow-up study of multiple sclerosis patients. Mult Scler. 2000;6(6):373-7.

47. Hofstetter L, Naegelin Y, Filli L, Kuster P, Traud S, Smieskova $\mathrm{R}$, et al. Progression in disability and regional grey matter atrophy in relapsing-remitting multiple sclerosis. Mult Scler. 2014;20(2):202-13. doi:10.1177/1352458513493034. 
48. Kalkers NF, Bergers L, de Groot V, Lazeron RH, van Walderveen MA, Uitdehaag BM, et al. Concurrent validity of the MS Functional Composite using MRI as a biological disease marker. Neurology. 2001;56(2):215-9.

49. Cohen JA, Cutter GR, Fischer JS, Goodman AD, Heidenreich FR, Kooijmans MF, et al. Benefit of interferon $\beta$-1a on MSFC progression in secondary progressive MS. Neurology. 2002;59(5):679-87.

50. Costelloe L, O'Rourke K, McGuigan C, Walsh C, Tubridy N, Hutchinson M. The longitudinal relationship between the patient-reported Multiple Sclerosis Impact Scale and the clinician-assessed Multiple Sclerosis Functional Composite. Mult Scler. 2008;14(2):255-8. doi:10.1177/1352458507081274.

51. Ozakbas S, Cagiran I, Ormeci B, Idiman E. Correlations between multiple sclerosis functional composite, expanded disability status scale and health-related quality of life during and after treatment of relapses in patients with multiple sclerosis. J Neurol Sci. 2004;218(1-2):3-7. doi:10.1016/j.jns.2003.09.015.

52. Honarmand K, Akbar N, Kou N, Feinstein A. Predicting employment status in multiple sclerosis patients: the utility of the MS functional composite. J Neurol. 2011;258(2):244-9. doi:10.1007/s00415-010-5736-8.

53. Shawaryn MA, Schultheis MT, Garay E, Deluca J. Assessing functional status: exploring the relationship between the multiple sclerosis functional composite and driving. Arch Phys Med Rehabil. 2002;83(8):1123-9.

54. Kempen JC, de Groot V, Knol DL, Polman CH, Lankhorst GJ, Beckerman H. Community walking can be assessed using a 10-metre timed walk test. Mult Scler. 2011;17(8):980-90. doi:10.1177/1352458511403641.

55. Goldman MD, Motl RW, Scagnelli J, Pula JH, Sosnoff JJ, Cadavid D. Clinically meaningful performance benchmarks in MS: timed 25-foot walk and the real world. Neurology. 2013;81(21):1856-63. doi:10.1212/01.wnl.0000436065.97642. d2.

56. Goldman MD, Marrie RA, Cohen JA. Evaluation of the sixminute walk in multiple sclerosis subjects and healthy controls. Mult Scler. 2008;14(3):383-90. doi:10.1177/13524585070 82607.

57. Kragt JJ, van der Linden FA, Nielsen JM, Uitdehaag BM, Polman $\mathrm{CH}$. Clinical impact of $20 \%$ worsening on Timed 25 -foot Walk and 9-hole Peg Test in multiple sclerosis. Mult Scler. 2006;12(5):594-8.

58. Gronwall DM. Paced auditory serial-addition task: a measure of recovery from concussion. Percept Mot Skills. 1977;44(2):367-73. doi:10.2466/pms.1977.44.2.367.

59. Chiaravalloti ND, DeLuca J. Cognitive impairment in multiple sclerosis. Lancet Neurol. 2008;7(12):1139-51. doi:10.1016/ S1474-4422(08)70259-X

60. Nagels G, Geentjens L, Kos D, Vleugels L, D'Hooghe MB, Van Asch P, et al. Paced visual serial addition test in multiple sclerosis. Clin Neurol Neurosurg. 2005;107(3):218-22. doi:10.1016/ j.clineuro.2004.11.016.

61. Cohen JA, Cutter GR, Fischer JS, Goodman AD, Heidenreich FR, Jak AJ, et al. Use of the multiple sclerosis functional composite as an outcome measure in a phase 3 clinical trial. Arch Neurol. 2001;58(6):961-7.

62. Benedict RH, Duquin JA, Jurgensen S, Rudick RA, Feitcher J, Munschauer FE, et al. Repeated assessment of neuropsychological deficits in multiple sclerosis using the Symbol Digit Modalities Test and the MS Neuropsychological Screening Questionnaire. Mult Scler. 2008;14(7):940-6. doi:10.1177/ 1352458508090923.

63. Ontaneda D, LaRocca N, Coetzee T, Rudick R, Force NMT. Revisiting the multiple sclerosis functional composite: proceedings from the National Multiple Sclerosis Society (NMSS)
Task Force on Clinical Disability Measures. Mult Scler. 2012;18(8):1074-80. doi:10.1177/1352458512451512.

64. Walker LA, Cheng A, Berard J, Berrigan LI, Rees LM, Freedman MS. Tests of information processing speed: what do people with multiple sclerosis think about them? Int J MS Care. 2012;14(2):92-9. doi:10.7224/1537-2073-14.2.92.

65. Benedict RH. Effects of using same- versus alternate-form memory tests during short-interval repeated assessments in multiple sclerosis. J Int Neuropsychol Soc. 2005;11(6):727-36. doi:10.1017/S1355617705050782.

66. Sonder JM, Burggraaff J, Knol DL, Polman CH, Uitdehaag BM. Comparing long-term results of PASAT and SDMT scores in relation to neuropsychological testing in multiple sclerosis. Mult Scler. 2014;20(4):481-8. doi:10.1177/1352458513501570.

67. Papadopoulou A, Muller-Lenke N, Naegelin Y, Kalt G, Bendfeldt K, Kuster P, et al. Contribution of cortical and white matter lesions to cognitive impairment in multiple sclerosis. Mult Scler. 2013;19(10):1290-6. doi:10.1177/1352458513475490.

68. Yu HJ, Christodoulou C, Bhise V, Greenblatt D, Patel Y, Serafin $\mathrm{D}$, et al. Multiple white matter tract abnormalities underlie cognitive impairment in RRMS. Neuroimage. 2012;59(4): 3713-22. doi:10.1016/j.neuroimage.2011.10.053.

69. Benedict RH, Cookfair D, Gavett R, Gunther M, Munschauer F, Garg N, et al. Validity of the minimal assessment of cognitive function in multiple sclerosis (MACFIMS). J Int Neuropsychol Soc. 2006;12(4):549-58.

70. Portaccio E, Goretti B, Zipoli V, Iudice A, Pina DD, Malentacchi GM, et al. Reliability, practice effects, and change indices for Rao's Brief Repeatable Battery. Mult Scler. 2010;16(5):611-7. doi:10.1177/1352458510362818.

71. Benedict RH, Bruce JM, Dwyer MG, Abdelrahman N, Hussein S, Weinstock-Guttman B, et al. Neocortical atrophy, third ventricular width, and cognitive dysfunction in multiple sclerosis. Arch Neurol. 2006;63(9):1301-6. doi:10.1001/archneur.63.9. 1301.

72. Benedict RH, Weinstock-Guttman B, Fishman I, Sharma J, Tjoa $\mathrm{CW}$, Bakshi R. Prediction of neuropsychological impairment in multiple sclerosis: comparison of conventional magnetic resonance imaging measures of atrophy and lesion burden. Arch Neurol. 2004;61(2):226-30. doi:10.1001/archneur.61.2.226.

73. Balcer LJ, Miller DH, Reingold SC, Cohen JA. Vision and vision-related outcome measures in multiple sclerosis. Brain. 2015;138(Pt 1):11-27. doi:10.1093/brain/awu335.

74. Balcer LJ, Baier ML, Cohen JA, Kooijmans MF, Sandrock AW, Nano-Schiavi ML, et al. Contrast letter acuity as a visual component for the Multiple Sclerosis Functional Composite. Neurology. 2003;61(10):1367-73.

75. Wu GF, Schwartz ED, Lei T, Souza A, Mishra S, Jacobs DA, et al. Relation of vision to global and regional brain MRI in multiple sclerosis. Neurology. 2007;69(23):2128-35. doi:10. 1212/01.wnl.0000278387.15090.5a.

76. Balcer LJ, Frohman EM. Evaluating loss of visual function in multiple sclerosis as measured by low-contrast letter acuity. Neurology. 2010;74(Suppl 3):S16-23. doi:10.1212/WNL. 0b013e3181dbb664.

77. Balcer LJ, Galetta SL, Calabresi PA, Confavreux C, Giovannoni G, Havrdova E, et al. Natalizumab reduces visual loss in patients with relapsing multiple sclerosis. Neurology. 2007;68(16): 1299-304. doi:10.1212/01.wnl.0000259521.14704.a8.

78. Uitdehaag BM, Ader HJ, Roosma TJ, de Groot V, Kalkers NF, Polman CH. Multiple sclerosis functional composite: impact of reference population and interpretation of changes. Mult Scler. 2002;8(5):366-71.

79. Fox RJ, Lee JC, Rudick RA. Optimal reference population for the multiple sclerosis functional composite. Mult Scler. 2007;13(7):909-14. doi:10.1177/1352458507076950. 
80. Schwid SR, Goodman AD, McDermott MP, Bever CF, Cook SD. Quantitative functional measures in MS: what is a reliable change? Neurology. 2002;58(8):1294-6.

81. Food and Drug Administration. Guidance for industry: patientreported outcome measures: use in medical product development to support labeling claims. http://www.fdagov/downloads/ drugs/guidancecomplianceregulatoryinformation/guidances/ucm 193282pdf. December 2009.

82. Beck AT, Ward CH, Mendelson M, Mock J, Erbaugh J. An inventory for measuring depression. Arch Gen Psychiatry. 1961;4:561-71.

83. Bergner M, Bobbitt RA, Carter WB, Gilson BS. The Sickness Impact Profile: development and final revision of a health status measure. Med Care. 1981;19(8):787-805.

84. Cella DF, Dineen K, Arnason B, Reder A, Webster KA, Karabatsos G, et al. Validation of the functional assessment of multiple sclerosis quality of life instrument. Neurology. 1996;47(1):129-39.

85. Ferrans CE, Powers MJ. Quality of life index: development and psychometric properties. ANS Adv Nurs Sci. 1985;8(1):15-24.

86. Fischer JS, LaRocca NG, Miller DM, Ritvo PG, Andrews H, Paty D. Recent developments in the assessment of quality of life in multiple sclerosis (MS). Mult Scler. 1999;5(4):251-9.

87. Fisk JD, Brown MG, Sketris IS, Metz LM, Murray TJ, Stadnyk KJ. A comparison of health utility measures for the evaluation of multiple sclerosis treatments. J Neurol Neurosurg Psychiatry. 2005;76(1):58-63. doi:10.1136/jnnp.2003.017897.

88. Fisk JD, Doble SE. Construction and validation of a fatigue impact scale for daily administration (D-FIS). Qual Life Res. 2002;11(3):263-72.

89. Fisk JD, Pontefract A, Ritvo PG, Archibald CJ, Murray TJ. The impact of fatigue on patients with multiple sclerosis. Can J Neurol Sci. 1994;21(1):9-14.

90. Ford HL, Gerry E, Tennant A, Whalley D, Haigh R, Johnson $\mathrm{MH}$. Developing a disease-specific quality of life measure for people with multiple sclerosis. Clin Rehabil. 2001;15(3): 247-58.

91. Gold SM, Heesen C, Schulz H, Guder U, Monch A, Gbadamosi $\mathrm{J}$, et al. Disease specific quality of life instruments in multiple sclerosis: validation of the Hamburg Quality of Life Questionnaire in Multiple Sclerosis (HAQUAMS). Mult Scler. 2001;7(2): 119-30.

92. Hobart J, Lamping D, Fitzpatrick R, Riazi A, Thompson A. The Multiple Sclerosis Impact Scale (MSIS-29): a new patient-based outcome measure. Brain. 2001;124(Pt 5):962-73.

93. Hobart JC, Riazi A, Lamping DL, Fitzpatrick R, Thompson AJ. Measuring the impact of MS on walking ability: the 12-Item MS Walking Scale (MSWS-12). Neurology. 2003;60(1):31-6.

94. Honarmand K, Feinstein A. Validation of the Hospital Anxiety and Depression Scale for use with multiple sclerosis patients. Mult Scler. 2009;15(12):1518-24. doi:10.1177/13524585093 47150 .

95. Kroenke K, Spitzer RL, Williams JB. The PHQ-9: validity of a brief depression severity measure. $\mathrm{J}$ Gen Intern Med. 2001;16(9):606-13.

96. Melin R, Fugl-Meyer KS, Fugl-Meyer AR. Life satisfaction in 18- to 64-year-old Swedes: in relation to education, employment situation, health and physical activity. J Rehabil Med. 2003;35(2):84-90.

97. Mokkink LB, Knol DL, Uitdehaag BM. Factor structure of Guy's Neurological Disability Scale in a sample of Dutch patients with multiple sclerosis. Mult Scler. 2011;17(12): 1498-503. doi:10.1177/1352458511413098.

98. Mokkink LB, Knol DL, van der Linden FH, Sonder JM, D'Hooghe M, Uitdehaag BM. The Arm Function in Multiple Sclerosis Questionnaire (AMSQ): development and validation of a new tool using IRT methods. Disabil Rehabil. 2015. doi:10. 3109/09638288.2015.1027005.

99. Mowry EM, Loguidice MJ, Daniels AB, Jacobs DA, Markowitz $\mathrm{CE}$, Galetta SL, et al. Vision related quality of life in multiple sclerosis: correlation with new measures of low and high contrast letter acuity. J Neurol Neurosurg Psychiatry. 2009;80(7):767-72. doi:10.1136/jnnp.2008.165449.

100. Ozakbas S, Akdede BB, Kosehasanogullari G, Aksan O, Idiman E. Difference between generic and multiple sclerosis-specific quality of life instruments regarding the assessment of treatment efficacy. J Neurol Sci. 2007;256(1-2):30-4. doi:10.1016/j.jns. 2007.01.080.

101. Pfennings L, Cohen L, Ader H, Polman C, Lankhorst G, Smits $\mathrm{R}$, et al. Exploring differences between subgroups of multiple sclerosis patients in health-related quality of life. J Neurol. 1999;246(7):587-91.

102. Simeoni M, Auquier P, Fernandez O, Flachenecker P, Stecchi S, Constantinescu $\mathrm{C}$, et al. Validation of the Multiple Sclerosis International Quality of Life questionnaire. Mult Scler. 2008;14(2):219-30. doi:10.1177/1352458507080733.

103. Vickrey BG, Hays RD, Harooni R, Myers LW, Ellison GW. A health-related quality of life measure for multiple sclerosis. Qual Life Res. 1995;4(3):187-206.

104. Ware JE Jr, Sherbourne CD. The MOS 36-item short-form health survey (SF-36). I. Conceptual framework and item selection. Med Care. 1992;30(6):473-83.

105. Wynia K, Middel B, van Dijk JP, de Ruiter H, de Keyser J, Reijneveld SA. The Multiple Sclerosis impact Profile (MSIP). Development and testing psychometric properties of an ICFbased health measure. Disabil Rehabil. 2008;30(4):261-74. doi:10.1080/09638280701256868.

106. Cohen RA, Kessler HR, Fischer M. The Extended Disability Status Scale (EDSS) as a predictor of impairments of functional activities of daily living in multiple sclerosis. J Neurol Sci. 1993;115(2):132-5.

107. Farrell B, Godwin J, Richards S, Warlow C. The United Kingdom transient ischaemic attack (UK-TIA) aspirin trial: final results. J Neurol Neurosurg Psychiatry. 1991;54(12):1044-54.

108. Rankin J. Cerebral vascular accidents in patients over the age of 60. II. Prognosis. Scott Med J. 1957;2(5):200-15.

109. Mahoney FI, Barthel DW. Functional evaluation: The Barthel index. Md State Med J. 1965;14:61-5.

110. Airlie J, Baker GA, Smith SJ, Young CA. Measuring the impact of multiple sclerosis on psychosocial functioning: the development of a new self-efficacy scale. Clin Rehabil. 2001;15(3):259-65.

111. Smith SJ, Young CA. The role of affect on the perception of disability in multiple sclerosis. Clin Rehabil. 2000;14(1):50-4.

112. Berrigan LI, Fisk JD, Patten SB, Tremlett H, Wolfson C, Warren $\mathrm{S}$, et al. Health-related quality of life in multiple sclerosis: direct and indirect effects of comorbidity. Neurology. 2016. doi:10. 1212/WNL.0000000000002564.

113. Sprangers MA, Schwartz CE. Integrating response shift into health-related quality of life research: a theoretical model. Soc Sci Med. 1999;48(11):1507-15.

114. Cappelleri JC, Jason Lundy J, Hays RD. Overview of classical test theory and item response theory for the quantitative assessment of items in developing patient-reported outcomes measures. Clin Ther. 2014;36(5):648-62. doi:10.1016/j. clinthera.2014.04.006.

115. van Munster ETL. Klinische en paraklinische parameters in het verloop van multiple sclerose. Thesis. 1991.

116. Filippi M, Rocca MA, Ciccarelli O, De Stefano N, Evangelou N, Kappos L, et al. MRI criteria for the diagnosis of multiple sclerosis: MAGNIMS consensus guidelines. Lancet Neurol. 2016;15(3):292-303. doi:10.1016/S1474-4422(15)00393-2. 
117. McDonald WI, Miller DH, Thompson AJ. Are magnetic resonance findings predictive of clinical outcome in therapeutic trials in multiple sclerosis? The dilemma of interferon-beta. Ann Neurol. 1994;36(1):14-8. doi:10.1002/ana.410360106.

118. Fisniku LK, Brex PA, Altmann DR, Miszkiel KA, Benton CE, Lanyon R, et al. Disability and T2 MRI lesions: a 20-year follow-up of patients with relapse onset of multiple sclerosis. Brain. 2008;131(Pt 3):808-17. doi:10.1093/brain/awm329.

119. Brex PA, Ciccarelli O, O'Riordan JI, Sailer M, Thompson AJ, Miller DH. A longitudinal study of abnormalities on MRI and disability from multiple sclerosis. $N$ Engl J Med. 2002;346(3):158-64. doi:10.1056/NEJMoa011341.

120. O'Riordan JI, Gawne Cain M, Coles A, Wang L, Compston DA, Tofts $\mathrm{P}$, et al. T1 hypointense lesion load in secondary progressive multiple sclerosis: a comparison of pre versus post contrast loads and of manual versus semi automated threshold techniques for lesion segmentation. Mult Scler. 1998;4(5): 408-12.

121. Tintore M, Rovira A, Rio J, Otero-Romero S, Arrambide G, Tur $\mathrm{C}$, et al. Defining high, medium and low impact prognostic factors for developing multiple sclerosis. Brain. 2015;138(Pt 7):1863-74. doi:10.1093/brain/awv105.

122. Bermel RA, You X, Foulds P, Hyde R, Simon JH, Fisher E, et al. Predictors of long-term outcome in multiple sclerosis patients treated with interferon beta. Ann Neurol. 2013;73(1):95-103. doi:10.1002/ana.23758.

123. Sormani MP, Bonzano L, Roccatagliata L, Cutter GR, Mancardi GL, Bruzzi P. Magnetic resonance imaging as a potential surrogate for relapses in multiple sclerosis: a meta-analytic approach. Ann Neurol. 2009;65(3):268-75. doi:10.1002/ana. 21606.

124. Dobson R, Rudick RA, Turner B, Schmierer K, Giovannoni G. Assessing treatment response to interferon- $\beta$ : is there a role for MRI? Neurology. 2014;82(3):248-54. doi:10.1212/WNL. 0000000000000036.

125. Sormani MP, Bonzano L, Roccatagliata L, Mancardi GL, Uccelli A, Bruzzi P. Surrogate endpoints for EDSS worsening in multiple sclerosis. A meta-analytic approach. Neurology. 2010;75(4):302-9. doi:10.1212/WNL.0b013e3181ea15aa.

126. Sormani MP, Stubinski B, Cornelisse P, Rocak S, Li D, De Stefano N. Magnetic resonance active lesions as individual-level surrogate for relapses in multiple sclerosis. Mult Scler. 2011;17(5):541-9. doi:10.1177/1352458510391837.

127. Geurts JJ, Barkhof F. Grey matter pathology in multiple sclerosis. Lancet Neurol. 2008;7(9):841-51. doi:10.1016/S14744422(08)70191-1.

128. Kalkers NF, Ameziane N, Bot JC, Minneboo A, Polman CH, Barkhof F. Longitudinal brain volume measurement in multiple sclerosis: rate of brain atrophy is independent of the disease subtype. Arch Neurol. 2002;59(10):1572-6.

129. Miller DH, Barkhof F, Frank JA, Parker GJ, Thompson AJ. Measurement of atrophy in multiple sclerosis: pathological basis, methodological aspects and clinical relevance. Brain. 2002;125(Pt 8):1676-95.

130. Henry RG, Shieh M, Okuda DT, Evangelista A, Gorno-Tempini ML, Pelletier D. Regional grey matter atrophy in clinically isolated syndromes at presentation. J Neurol Neurosurg Psychiatry. 2008;79(11):1236-44. doi:10.1136/jnnp.2007.134825.

131. Fisher E, Lee JC, Nakamura K, Rudick RA. Gray matter atrophy in multiple sclerosis: a longitudinal study. Ann Neurol. 2008;64(3):255-65. doi:10.1002/ana.21436.

132. van Munster CE, Jonkman LE, Weinstein HC, Uitdehaag BM, Geurts JJ. Gray matter damage in multiple sclerosis: impact on clinical symptoms. Neuroscience. 2015;303:446-61. doi:10. 1016/j.neuroscience.2015.07.006.
133. Simon JH, Jacobs LD, Campion MK, Rudick RA, Cookfair DL, Herndon RM. A longitudinal study of brain atrophy in relapsing multiple sclerosis. The Multiple Sclerosis Collaborative Research Group (MSCRG). Neurology. 1999;53(1):139-48.

134. Ashburner J, Friston KJ. Voxel-based morphometry-the methods. Neuroimage. 2000;11(6 Pt 1):805-21. doi:10.1006/ nimg.2000.0582.

135. Fischl B, Dale AM. Measuring the thickness of the human cerebral cortex from magnetic resonance images. Proc Natl Acad Sci USA. 2000;97(20):11050-5. doi:10.1073/pnas. 200033797.

136. Smith SM, Zhang Y, Jenkinson M, Chen J, Matthews PM, Federico A, et al. Accurate, robust, and automated longitudinal and cross-sectional brain change analysis. Neuroimage. 2002;17(1):479-89.

137. Fisniku LK, Chard DT, Jackson JS, Anderson VM, Altmann DR, Miszkiel KA, et al. Gray matter atrophy is related to longterm disability in multiple sclerosis. Ann Neurol. 2008;64(3):247-54. doi:10.1002/ana.21423.

138. Anderson VM, Fisniku LK, Altmann DR, Thompson AJ, Miller DH. MRI measures show significant cerebellar gray matter volume loss in multiple sclerosis and are associated with cerebellar dysfunction. Mult Scler. 2009;15(7):811-7. doi:10.1177/ 1352458508101934.

139. Lycklama G, Thompson A, Filippi M, Miller D, Polman C, Fazekas F, et al. Spinal-cord MRI in multiple sclerosis. Lancet Neurol. 2003;2(9):555-62.

140. Sicotte NL, Kern KC, Giesser BS, Arshanapalli A, Schultz A, Montag M, et al. Regional hippocampal atrophy in multiple sclerosis. Brain. 2008;131(Pt 4):1134-41. doi:10.1093/brain/ awn030.

141. Houtchens MK, Benedict RH, Killiany R, Sharma J, Jaisani Z, Singh B, et al. Thalamic atrophy and cognition in multiple sclerosis. Neurology. 2007;69(12):1213-23. doi:10.1212/01. wnl.0000276992.17011.b5.

142. Calabrese M, Filippi M, Rovaris M, Bernardi V, Atzori M, Mattisi I, et al. Evidence for relative cortical sparing in benign multiple sclerosis: a longitudinal magnetic resonance imaging study. Mult Scler. 2009;15(1):36-41. doi:10.1177/ 1352458508096686.

143. Rocca MA, Mesaros S, Pagani E, Sormani MP, Comi G, Filippi M. Thalamic damage and long-term progression of disability in multiple sclerosis. Radiology. 2010;257(2):463-9. doi:10.1148/ radiol.10100326.

144. Valsasina P, Rocca MA, Horsfield MA, Absinta M, Messina R, Caputo D, et al. Regional cervical cord atrophy and disability in multiple sclerosis: a voxel-based analysis. Radiology. 2013;266(3):853-61. doi:10.1148/radiol.12120813.

145. Lukas C, Sombekke MH, Bellenberg B, Hahn HK, Popescu V, Bendfeldt $\mathrm{K}$, et al. Relevance of spinal cord abnormalities to clinical disability in multiple sclerosis: MR imaging findings in a large cohort of patients. Radiology. 2013;269(2):542-52. doi:10.1148/radiol.13122566.

146. Rocca MA, Valsasina P, Damjanovic D, Horsfield MA, Mesaros $\mathrm{S}$, Stosic-Opincal T, et al. Voxel-wise mapping of cervical cord damage in multiple sclerosis patients with different clinical phenotypes. J Neurol Neurosurg Psychiatry. 2013;84(1):35-41. doi:10.1136/jnnp-2012-303821.

147. Kearney H, Rocca MA, Valsasina P, Balk L, Sastre-Garriga J, Reinhardt $\mathbf{J}$, et al. Magnetic resonance imaging correlates of physical disability in relapse onset multiple sclerosis of long disease duration. Mult Scler. 2014;20(1):72-80. doi:10.1177/ 1352458513492245.

148. De Stefano N, Airas L, Grigoriadis N, Mattle HP, O'Riordan J, Oreja-Guevara $\mathrm{C}$, et al. Clinical relevance of brain volume 
measures in multiple sclerosis. CNS Drugs. 2014;28(2):147-56. doi:10.1007/s40263-014-0140-z.

149. Ziemssen T, Derfuss T, de Stefano N, Giovannoni G, Palavra F, Tomic D, et al. Optimizing treatment success in multiple sclerosis. J Neurol. 2016;263(6):1053-65. doi:10.1007/s00415-0157986-y.

150. Sormani MP, Arnold DL, De Stefano N. Treatment effect on brain atrophy correlates with treatment effect on disability in multiple sclerosis. Ann Neurol. 2014;75(1):43-9. doi:10.1002/ ana.24018.

151. Tsivgoulis G, Katsanos AH, Grigoriadis N, Hadjigeorgiou GM, Heliopoulos I, Kilidireas C, et al. The effect of disease modifying therapies on brain atrophy in patients with relapsingremitting multiple sclerosis: a systematic review and metaanalysis. PLoS One. 2015;10(3):e0116511. doi:10.1371/journal. pone. 0116511

152. Bermel RA, Bakshi R. The measurement and clinical relevance of brain atrophy in multiple sclerosis. Lancet Neurol. 2006;5(2):158-70. doi:10.1016/S1474-4422(06)70349-0.

153. Zivadinov R, Reder AT, Filippi M, Minagar A, Stuve O, Lassmann $\mathrm{H}$, et al. Mechanisms of action of disease-modifying agents and brain volume changes in multiple sclerosis. Neurology. 2008;71(2):136-44. doi:10.1212/01.wnl.0000316810.01120.05.

154. Giorgio A, Battaglini M, Smith SM, De Stefano N. Brain atrophy assessment in multiple sclerosis: importance and limitations. Neuroimaging Clin N Am. 2008;18(4):675-86. doi:10. 1016/j.nic.2008.06.007.

155. van Waesberghe JH, van Walderveen MA, Castelijns JA, Scheltens P, Lycklama a Nijeholt GJ, Polman CH, et al. Patterns of lesion development in multiple sclerosis: longitudinal observations with T1-weighted spin-echo and magnetization transfer MR. AJNR Am J Neuroradiol. 1998;19(4):675-83.

156. van Walderveen MA, Kamphorst W, Scheltens P, van Waesberghe JH, Ravid R, Valk J, et al. Histopathologic correlate of hypointense lesions on T1-weighted spin-echo MRI in multiple sclerosis. Neurology. 1998;50(5):1282-8.

157. van Walderveen MA, Barkhof F, Hommes OR, Polman $\mathrm{CH}$, Tobi H, Frequin ST, et al. Correlating MRI and clinical disease activity in multiple sclerosis: relevance of hypointense lesions on short-TR/short-TE (T1-weighted) spin-echo images. Neurology. 1995;45(9):1684-90.

158. Truyen L, van Waesberghe $\mathrm{JH}$, van Walderveen MA, van Oosten BW, Polman CH, Hommes OR, et al. Accumulation of hypointense lesions ("black holes") on T1 spin-echo MRI correlates with disease progression in multiple sclerosis. Neurology. 1996;47(6):1469-76.

159. Giorgio A, Stromillo ML, Bartolozzi ML, Rossi F, Battaglini M, De Leucio A, et al. Relevance of hypointense brain MRI lesions for long-term worsening of clinical disability in relapsing multiple sclerosis. Mult Scler. 2014;20(2):214-9. doi:10.1177/ 1352458513494490.

160. Filippi M, Rovaris M, Rocca MA, Sormani MP, Wolinsky JS, Comi $\mathrm{G}$, et al. Glatiramer acetate reduces the proportion of new MS lesions evolving into "black holes". Neurology. 2001;57(4):731-3.

161. Filippi M, Rocca MA, Pagani E, De Stefano N, Jeffery D, Kappos L, et al. Placebo-controlled trial of oral laquinimod in multiple sclerosis: MRI evidence of an effect on brain tissue damage. J Neurol Neurosurg Psychiatry. 2014;85(8):851-8. doi:10.1136/jnnp-2013-306132.

162. Dalton CM, Miszkiel KA, Barker GJ, MacManus DG, Pepple TI, Panzara M, et al. Effect of natalizumab on conversion of gadolinium enhancing lesions to $\mathrm{T} 1$ hypointense lesions in relapsing multiple sclerosis. J Neurol. 2004;251(4):407-13. doi:10.1007/s00415-004-0332-4.

163. Barkhof F, van Waesberghe JH, Filippi M, Yousry T, Miller $\mathrm{DH}$, Hahn D, et al. $\mathrm{T}(1)$ hypointense lesions in secondary progressive multiple sclerosis: effect of interferon beta-1b treatment. Brain. 2001;124(Pt 7):1396-402.

164. Schoonheim MM, Meijer KA, Geurts JJ. Network collapse and cognitive impairment in multiple sclerosis. Front Neurol. 2015;6:82. doi:10.3389/fneur.2015.00082.

165. Rovaris M, Gass A, Bammer R, Hickman SJ, Ciccarelli O, Miller DH, et al. Diffusion MRI in multiple sclerosis. Neurology. 2005; 65(10):1526-32. doi:10.1212/01.wnl.0000184471.83948.e0.

166. Tortorella C, Viti B, Bozzali M, Sormani MP, Rizzo G, Gilardi $\mathrm{MF}$, et al. A magnetization transfer histogram study of normalappearing brain tissue in MS. Neurology. 2000;54(1):186-93.

167. Schmierer K, Tozer DJ, Scaravilli F, Altmann DR, Barker GJ, Tofts PS, et al. Quantitative magnetization transfer imaging in postmortem multiple sclerosis brain. J Magn Reson Imaging. 2007;26(1):41-51. doi:10.1002/jmri.20984.

168. Gabilondo I, Martinez-Lapiscina EH, Martinez-Heras E, FragaPumar E, Llufriu S, Ortiz S, et al. Trans-synaptic axonal degeneration in the visual pathway in multiple sclerosis. Ann Neurol. 2014;75(1):98-107. doi:10.1002/ana.24030.

169. Saidha S, Syc SB, Ibrahim MA, Eckstein C, Warner CV, Farrell SK, et al. Primary retinal pathology in multiple sclerosis as detected by optical coherence tomography. Brain. 2011;134(Pt 2):518-33. doi:10.1093/brain/awq346.

170. Green AJ, McQuaid S, Hauser SL, Allen IV, Lyness R. Ocular pathology in multiple sclerosis: retinal atrophy and inflammation irrespective of disease duration. Brain. 2010;133(Pt 6):1591-601. doi:10.1093/brain/awq080.

171. Talman LS, Bisker ER, Sackel DJ, Long DA Jr, Galetta KM, Ratchford JN, et al. Longitudinal study of vision and retinal nerve fiber layer thickness in multiple sclerosis. Ann Neurol. 2010;67(6):749-60. doi:10.1002/ana.22005.

172. Petzold A, de Boer JF, Schippling S, Vermersch P, Kardon R, Green A, et al. Optical coherence tomography in multiple sclerosis: a systematic review and meta-analysis. Lancet Neurol. 2010;9(9):921-32. doi:10.1016/S1474-4422(10)70168-X.

173. Herrero R, Garcia-Martin E, Almarcegui C, Ara JR, RodriguezMena D, Martin J, et al. Progressive degeneration of the retinal nerve fiber layer in patients with multiple sclerosis. Invest Ophthalmol Vis Sci. 2012;53(13):8344-9. doi:10.1167/iovs.12-10362.

174. Siger M, Dziegielewski K, Jasek L, Bieniek M, Nicpan A, Nawrocki J, et al. Optical coherence tomography in multiple sclerosis: thickness of the retinal nerve fiber layer as a potential measure of axonal loss and brain atrophy. J Neurol. 2008;255(10):1555-60. doi:10.1007/s00415-008-0985-5.

175. Saidha S, Sotirchos ES, Oh J, Syc SB, Seigo MA, Shiee N, et al. Relationships between retinal axonal and neuronal measures and global central nervous system pathology in multiple sclerosis. JAMA Neurol. 2013;70(1):34-43. doi:10.1001/jamaneurol.2013. 573.

176. Trip SA, Schlottmann PG, Jones SJ, Altmann DR, GarwayHeath DF, Thompson AJ, et al. Retinal nerve fiber layer axonal loss and visual dysfunction in optic neuritis. Ann Neurol. 2005;58(3):383-91. doi:10.1002/ana.20575.

177. Parisi V, Manni G, Spadaro M, Colacino G, Restuccia R, Marchi $\mathrm{S}$, et al. Correlation between morphological and functional retinal impairment in multiple sclerosis patients. Invest Ophthalmol Vis Sci. 1999;40(11):2520-7.

178. Henderson AP, Altmann DR, Trip AS, Kallis C, Jones SJ, Schlottmann PG, et al. A serial study of retinal changes following optic neuritis with sample size estimates for acute neuroprotection trials. Brain. 2010;133(9):2592-602. doi:10.1093/ brain/awq146.

179. Sakai RE, Feller DJ, Galetta KM, Galetta SL, Balcer LJ. Vision in multiple sclerosis: the story, structure-function correlations, and models for neuroprotection. J Neuroophthalmol. 2011;31(4):362-73. doi:10.1097/WNO.0b013e318238937f. 
180. Naismith RT, Tutlam NT, Xu J, Shepherd JB, Klawiter EC, Song SK, et al. Optical coherence tomography is less sensitive than visual evoked potentials in optic neuritis. Neurology. 2009;73(1):46-52. doi:10.1212/WNL.0b013e3181aaea32.

181. Jeanjean L, Castelnovo G, Carlander B, Villain M, Mura F, Dupeyron $\mathrm{G}$, et al. Retinal atrophy using optical coherence tomography (OCT) in 15 patients with multiple sclerosis and comparison with healthy subjects. Rev Neurol (Paris). 2008;164(11):927-34. doi:10.1016/j.neurol.2008.03.008.

182. Martinez-Lapiscina EH, Arnow S, Wilson JA, Saidha S, Preiningerova JL, Oberwahrenbrock $\mathrm{T}$, et al. Retinal thickness measured with optical coherence tomography and risk of disability worsening in multiple sclerosis: a cohort study. Lancet Neurol. 2016;15(6):574-84. doi:10.1016/S1474-4422(16)000 68-5.

183. Burkholder BM, Osborne B, Loguidice MJ, Bisker E, Frohman TC, Conger A, et al. Macular volume determined by optical coherence tomography as a measure of neuronal loss in multiple sclerosis. Arch Neurol. 2009;66(11):1366-72. doi:10.1001/ archneurol.2009.230.

184. Walter SD, Ishikawa H, Galetta KM, Sakai RE, Feller DJ, Henderson SB, et al. Ganglion cell loss in relation to visual disability in multiple sclerosis. Ophthalmology. 2012;119(6): 1250-7. doi:10.1016/j.ophtha.2011.11.032.

185. Oberwahrenbrock T, Ringelstein M, Jentschke S, Deuschle K, Klumbies K, Bellmann-Strobl J, et al. Retinal ganglion cell and inner plexiform layer thinning in clinically isolated syndrome. Mult Scler. 2013;19(14):1887-95. doi:10.1177/13524585134 89757.

186. Pierro L, Gagliardi M, Iuliano L, Ambrosi A, Bandello F. Retinal nerve fiber layer thickness reproducibility using seven different OCT instruments. Invest Ophthalmol Vis Sci. 2012;53(9):5912-20. doi:10.1167/iovs.11-8644.

187. Teunissen CE, Malekzadeh A, Leurs C, Bridel C, Killestein J. Body fluid biomarkers for multiple sclerosis-the long road to clinical application. Nat Rev Neurol. 2015;11(10):585-96. doi:10.1038/nrneurol.2015.173.

188. Petzold A, Tisdall MM, Girbes AR, Martinian L, Thom M, Kitchen N, et al. In vivo monitoring of neuronal loss in traumatic brain injury: a microdialysis study. Brain. 2011;134(Pt 2):464-83. doi:10.1093/brain/awq360.

189. Malmestrom C, Haghighi S, Rosengren L, Andersen O, Lycke J. Neurofilament light protein and glial fibrillary acidic protein as biological markers in MS. Neurology. 2003;61(12):1720-5.

190. Kuhle J, Plattner K, Bestwick JP, Lindberg RL, Ramagopalan SV, Norgren N, et al. A comparative study of CSF neurofilament light and heavy chain protein in MS. Mult Scler. 2013;19(12):1597-603. doi:10.1177/1352458513482374.

191. Petzold A. The prognostic value of CSF neurofilaments in multiple sclerosis at 15 -year follow-up. J Neurol Neurosurg Psychiatry. 2015;86(12):1388-90. doi:10.1136/jnnp-2014309827.

192. Burman J, Zetterberg H, Fransson M, Loskog AS, Raininko R, Fagius J. Assessing tissue damage in multiple sclerosis: a biomarker approach. Acta Neurol Scand. 2014;130(2):81-9. doi:10. 1111/ane.12239.

193. Petzold A, Steenwijk MD, Eikelenboom JM, Wattjes MP, Uitdehaag BM. Elevated CSF neurofilament proteins predict brain atrophy: a 15-year follow-up study. Mult Scler. 2016;22(9): 1154-62. doi:10.1177/1352458516645206.

194. Kuhle J, Disanto G, Lorscheider J, Stites T, Chen Y, Dahlke F, et al. Fingolimod and CSF neurofilament light chain levels in relapsing-remitting multiple sclerosis. Neurology. 2015;84(16): 1639-43. doi:10.1212/WNL.0000000000001491.

195. Gunnarsson M, Malmestrom C, Axelsson M, Sundstrom P, Dahle C, Vrethem M, et al. Axonal damage in relapsing multiple sclerosis is markedly reduced by natalizumab. Ann Neurol. 2011;69(1):83-9. doi:10.1002/ana.22247.

196. Doussau F, Augustine GJ. The actin cytoskeleton and neurotransmitter release: an overview. Biochimie. 2000;82(4):353-63.

197. Semra YK, Seidi OA, Sharief MK. Heightened intrathecal release of axonal cytoskeletal proteins in multiple sclerosis is associated with progressive disease and clinical disability. J Neuroimmunol. 2002;122(1-2):132-9.

198. Downing KH. Structural basis for the interaction of tubulin with proteins and drugs that affect microtubule dynamics. Annu Rev Cell Dev Biol. 2000;16:89-111. doi:10.1146/annurev.cellbio.16. 1.89 .

199. Checa A, Khademi M, Sar DG, Haeggstrom JZ, Lundberg JO, Piehl F, et al. Hexosylceramides as intrathecal markers of worsening disability in multiple sclerosis. Mult Scler. 2015;21(10):1271-9. doi:10.1177/1352458514561908.

200. Petzold A, Eikelenboom MJ, Gveric D, Keir G, Chapman M, Lazeron RH, et al. Markers for different glial cell responses in multiple sclerosis: clinical and pathological correlations. Brain. 2002;125(Pt 7):1462-73.

201. Hinsinger G, Galeotti N, Nabholz N, Urbach S, Rigau V, Demattei $\mathrm{C}$, et al. Chitinase 3-like proteins as diagnostic and prognostic biomarkers of multiple sclerosis. Mult Scler. 2015;21(10):1251-61. doi:10.1177/1352458514561906.

202. Kuhle J, Gaiottino J, Leppert D, Petzold A, Bestwick JP, Malaspina A, et al. Serum neurofilament light chain is a biomarker of human spinal cord injury severity and outcome. J Neurol Neurosurg Psychiatry. 2015;86(3):273-9. doi:10.1136/ jnnp-2013-307454.

203. Disanto G, Adiutori R, Dobson R, Martinelli V, Dalla Costa G, Runia $\mathrm{T}$, et al. Serum neurofilament light chain levels are increased in patients with a clinically isolated syndrome. J Neurol Neurosurg Psychiatry. 2016;87(2):126-9. doi:10.1136/ jnnp-2014-309690.

204. van der Voort LF, Vennegoor A, Visser A, Knol DL, Uitdehaag $\mathrm{BM}$, Barkhof $\mathrm{F}$, et al. Spontaneous MxA mRNA level predicts relapses in patients with recently diagnosed MS. Neurology. 2010;75(14):1228-33. doi:10.1212/WNL.0b013e3181f6c556.

205. van der Voort LF, Visser A, Knol DL, Oudejans CB, Polman $\mathrm{CH}$, Killestein J. Lack of interferon-beta bioactivity is associated with the occurrence of relapses in multiple sclerosis. Eur J Neurol. 2009;16(9):1049-52. doi:10.1111/j.1468-1331.2009. 02649.x.

206. Lublin FD. Disease activity free status in MS. Mult Scler Relat Disord. 2012;1(1):6-7. doi:10.1016/j.msard.2011.08.001.

207. Rotstein DL, Healy BC, Malik MT, Chitnis T, Weiner HL. Evaluation of no evidence of disease activity in a 7-year longitudinal multiple sclerosis cohort. JAMA Neurol. 2015;72(2):152-8. doi:10.1001/jamaneurol.2014.3537.

208. Sormani MP, De Stefano N. Defining and scoring response to IFN-beta in multiple sclerosis. Nat Rev Neurol. 2013;9(9):504-12. doi:10.1038/nrneurol.2013.146.

209. Popescu V, Agosta F, Hulst HE, Sluimer IC, Knol DL, Sormani MP, et al. Brain atrophy and lesion load predict long term disability in multiple sclerosis. J Neurol Neurosurg Psychiatry. 2013;84(10):1082-91. doi:10.1136/jnnp-2012-304094.

210. Filippi M, Preziosa P, Copetti M, Riccitelli G, Horsfield MA, Martinelli V, et al. Gray matter damage predicts the accumulation of disability 13 years later in MS. Neurology. 2013;81(20): 1759-67. doi:10.1212/01.wnl.0000435551.90824.d0.

211. Sormani MP, Rio J, Tintore M, Signori A, Li D, Cornelisse P, et al. Scoring treatment response in patients with relapsing multiple sclerosis. Mult Scler. 2013;19(5):605-12. doi:10.1177/ 1352458512460605.

212. Havrdova E, Galetta S, Hutchinson M, Stefoski D, Bates D, Polman $\mathrm{CH}$, et al. Effect of natalizumab on clinical and 
radiological disease activity in multiple sclerosis: a retrospective analysis of the Natalizumab Safety and Efficacy in RelapsingRemitting Multiple Sclerosis (AFFIRM) study. Lancet Neurol. 2009;8(3):254-60. doi:10.1016/S1474-4422(09)70021-3.

213. Menge T, Stuve O, Kieseier BC, Hartung HP. Alemtuzumab: the advantages and challenges of a novel therapy in MS. Neurology. 2014;83(1):87-97. doi:10.1212/WNL.0000000000000540.

214. Kappos L, De Stefano N, Freedman MS, Cree BA, Radue EW, Sprenger $\mathrm{T}$, et al. Inclusion of brain volume loss in a revised measure of 'no evidence of disease activity' (NEDA-4) in relapsing-remitting multiple sclerosis. Mult Scler. 2016;22(10): 1297-305. doi:10.1177/1352458515616701.

215. DSouza M, Burggraaff J, Steinheimer S, Kontschieder P, Morrison C, Dorn J et al. Accuracy of depth-sensing recordings in classifying Expanded Disability Status Scale subscores of motor dysfunction in patients with multiple sclerosis. American Academy of Neurology (AAN) poster presentation. 2016.
216. Bonzano L, Sormani MP, Tacchino A, Abate L, Mancardi GL, Uccelli A. Validation of a new quantitative and objective tool for the assessment of hand motor disability in multiple sclerosis. Mult Scler. 2011;17 (suppl 10):43.

217. Weikert M, Suh Y, Lane A, Sandroff B, Dlugonski D, Fernhall $\mathrm{B}$, et al. Accelerometry is associated with walking mobility, not physical activity, in persons with multiple sclerosis. Med Eng Phys. 2012;34(5):590-7. doi:10.1016/j.medengphy.2011.09.005.

218. Busby B, Lesko M, Federer L. Closing gaps between open software and public data in a hackathon setting: user-centered software prototyping. F1000 Res. 2016;5:672. doi:10.12688/ f1000research.8382.2.

219. Walker A, Ko N. Bringing medicine to the digital age via hackathons and beyond. J Med Syst. 2016;40(4):98. doi:10. 1007/s10916-016-0461-1. 